\title{
Feeding of carob (Ceratonia siliqua) to sheep infected with gastrointestinal nematodes reduces faecal egg counts and worm fecundity
}

Article

Accepted Version

Creative Commons: Attribution-Noncommercial-No Derivative Works 4.0

Saratsi, K., Hoste, H., Voutzourakis, N., Tzanidakis, N., Stefanakis, A., Thamsborg, S. M., Mueller-Harvey, I., Hadjigeorgiou, I. and Sotiraki, S. (2020) Feeding of carob (Ceratonia siliqua) to sheep infected with gastrointestinal nematodes reduces faecal egg counts and worm fecundity. Veterinary Parasitology, 284. 109200. ISSN 0304-4017 doi: https://doi.org/10.1016/j.vetpar.2020.109200 Available at https://centaur.reading.ac.uk/92265/

It is advisable to refer to the publisher's version if you intend to cite from the work. See Guidance on citing.

To link to this article DOI: http://dx.doi.org/10.1016/j.vetpar.2020.109200

Publisher: Elsevier

All outputs in CentAUR are protected by Intellectual Property Rights law, including copyright law. Copyright and IPR is retained by the creators or other copyright holders. Terms and conditions for use of this material are defined in the End User Agreement. 


\section{www.reading.ac.uk/centaur}

\section{CentAUR}

Central Archive at the University of Reading

Reading's research outputs online 
2 Feeding of carob (Ceratonia siliqua) to sheep infected with gastrointestinal nematodes

3 reduces faecal egg counts and worm fecundity

5 Katerina Saratsi ${ }^{\mathrm{a}, \mathrm{b}}$, Hervé Hoste ${ }^{\mathrm{c}, \mathrm{d}}$, Nikolaos Voutzourakis ${ }^{\mathrm{a}}$, Nikolaos Tzanidakis ${ }^{\mathrm{a}}$, 6 Alexandros Stefanakis ${ }^{\mathrm{a}}$, Stig Milan Thamsborg ${ }^{\mathrm{e}}$, Irene Mueller-Harvey ${ }^{\mathrm{f}}$, S., Ioannis Hadjigeorgiou $^{\mathrm{b}+}$, Smaragda Sotiraki ${ }^{\mathrm{a}+}$,

$9{ }^{a}$ Veterinary Research Institute, Hellenic Agricultural Organization-Demeter, Thermi 10 57001, Thessaloniki, Greece

$11{ }^{b}$ Department of Nutritional Physiology and Feeding, Faculty of Animal Science, Agricultural University of Athens, 11855 Athens, Greece ${ }^{\mathrm{c}}$ INRAE, UMR 1225 IHAP, 23 Chemin des Capelles, Toulouse F-31076, France 236,1 Earley Gate, Reading RG6 6AT, UK. 


\section{Abstract}

The present study explored the anthelmintic effects of condensed tannins (CT) in carob (Ceratonia siliqua) pods fed to sheep against gastrointestinal nematodes. Three independent in vivo trials tested whether i) carob pod (CaBP)-containing feed had an anthelmintic effect and if yes, which was the optimal concentration in the diet; ii) whether this effect could be attributed to tannins through the polyethylene glycol (PEG) test and iii) whether there were any synergistic effects when combined with another tannin-containing feed (e.g. sainfoin). In all trials 6-month old nematodenaive lambs, experimentally infected with both Haemonchus contortus and Trichostrongylus colubriformis, were used. Faecal egg counts (FEC) were performed regularly and at the end of each trial adult worm counts (AWC) and female worm fecundity were recorded. In trial 1, 35 lambs (five groups of seven lambs) were fed different $\mathrm{CaBP}$ concentrations ranging from $0 \%$ to $12 \% \mathrm{w} / \mathrm{w}$. FEC declined up to $39.2 \%$ only in the group fed with $12 \% \mathrm{CaBP}$, while a declining trend $(\mathrm{P}<0.06)$ was demonstrated for the AWC of T. colubriformis, which was associated with the increasing concentration of $\mathrm{CaBP}$ in feed. Female worm fecundity was reduced in groups fed $\mathrm{CaBP}$ for both parasites, however this was only significant for $H$. contortus $(\mathrm{P}<0.001)$, in a dose dependent manner. In trial 2 , four groups of six infected lambs each were used, which received the carob diets $\mathrm{CaBP}$ or $\mathrm{CaBP}+\mathrm{PEG}$, and the tannin-free diets with or without PEG (C or C+PEG). Results showed that FEC of Groups $\mathrm{C}, \mathrm{C}+\mathrm{PEG}$, and $\mathrm{CaBP}+\mathrm{PEG}$ were comparable throughout the trial, while the group receiving only CaBP showed lower FEC from DAY 25 onwards. AWC showed a reduction $(67.7 \%)$ only for $H$. contortus $(\mathrm{P}<0.03)$. Reversal of the anthelmintic effect of $\mathrm{CaBP}$ after PEG administration suggested that CT contributed to the anthelmintic action. However, no effect of CaBP was observed on $T$. 
51 colubriformis AWC and on female worm fecundity for both species. Finally, for trial

523 four groups of six lambs each received a diet based on $\mathrm{CaBP}$, sainfoin (S) or a 53 combination $(\mathrm{CaBP}+\mathrm{S})$ and were compared to a control (C) diet of lucerne. On DAY 5437 FEC values in groups $\mathrm{CaBP}+\mathrm{S}$ and $\mathrm{S}$ tended to be lower compared to the two other 55 groups $(\mathrm{C}, \mathrm{CaBP})$, while for AWCs no significant differences were observed for both 56 parasites. The fecundity of $H$. contortus and $T$. colubriformis demonstrated significant differences between the treated and control groups, with lower values in the animals receiving $\mathrm{CaBP}+\mathrm{S}$. Overall, the results supported the hypothesis that carob had an anthelmintic effect due to its $\mathrm{CT}$, but there was no clear indication of a synergistic effect with sainfoin.

61

Keywords: Carob, Sainfoin, Haemonchus contortus, Trichostrongylus colubriformis, 


\section{Introduction}

Infections by gastrointestinal nematodes (GIN) affect both health and welfare of grazing ruminants, causing anorexia, impaired digestion and nutrient absorption with related production losses, diarrhoea, anaemia and even death (Perry and Randolph, 1999; Stear et al., 2007; Hoste et al., 2016). Currently, the control of these parasites relies on repeated dosing with commercial anthelmintic drugs. However, the development of anthelmintic resistance in worm populations against one or multiple classes of anthelmintic has become a serious problem in several regions of the world, making it increasingly difficult to control parasitic infections (Kaplan, 2020). At the same time the increasing concerns of consumers about the presence of drug residues in foods and in the environment (McKellar, 1997) have stimulated the search for alternative or complementary solutions (Hoste and Torres-Acosta, 2011) within the context of organic farming and sustainable agriculture (Charlier et al., 2018).

91 Such alternatives include the use of bioactive plants with anthelmintic properties.

92 Many results indicate that such resources, because of the presence of plant secondary 93 metabolites (PSMs), might help to interfere with the biology of key-stages during 94 nematode cycle and to reduce the consequences of GIN infections in grazing 95 ruminants. Particular attention has been given to plants containing condensed tannins 96 (CT) and some related polyphenols (see reviews by Terrill et al., 2012; Hoste et al., 2015, 2016). Based on previous studies, the need to explore new plant resources to develop non-drug-based strategies for the integrated control of nematode parasites in

99 grazing ruminants has recently become a research priority in livestock production, 100 especially in ruminant breeding as also reviewed by Morgan et al, 2020. 
101 Small ruminants (sheep and goats) are a major component of the dairy sector in the

102 Mediterranean basin (Hadjigeorgiou et al., 2005). Sheep and goat production often

103 occupy marginal lands that are unsuitable for crop production but are rich in local

104 plants, such as rangeland vegetation, which can be exploited by animals as a feed

105 resource (Frutos et al., 2008; Méndez-Ortiz et al., 2018). Many rangeland plants also

106 contain PSMs, such as tannins (Papachristou et al., 2005) and several in vitro and in

107 vivo studies have evaluated their anthelmintic effects against GINs of small ruminants

108 (Manolaraki et al., 2010; Moreno-Gonzalo et al., 2012, 2013a,b, 2014; Arroyo-Lopez

109 et al., 2014; Silva Soares et al., 2018). Overall, CTs have been shown to directly or

110 indirectly interfere with the life cycle of several GINs and, therefore, CT-containing

111 plants, which also include many legumes, are proving to be beneficial nutritional

112 resources. However, a high degree of variability with respect to their anthelmintic

113 activity has also been recorded. Besides the total tannin concentration in ruminant

114 diets, recent studies have demonstrated that CT molecular composition or structural

115 characteristics can also affect anthelmintic activity (Mueller-Harvey et al., 2019).

116 Carob (Ceratonia siliqua) and sainfoin (Onobrychis viciifolia) are both resources of 117 the Fabaceae family and contain CTs. Carob is a leguminous tree that is widely 118 cultivated in the Mediterranean area. It is an important species both for economic and 119 environmental reasons (Batlle and Tous, 1997). Carob pods (fruits) are mostly used in 120 the food industry; pulp accounts for $90 \%$ by pod weight and seeds for $10 \%$. They 121 contain high sugar (48-56\%), but low protein (3-4\%) and lipid concentrations $(0.4-$ 122 0.8\%) (Marakis, 1996; Batlle and Tous, 1997). Moreover, ripe carob pods contain 123 high concentrations of CTs (16-20\% w/w DM) (Bravo et al., 1994; Batlle and Tous, 124 1997). This has been debated by Priolo et al. (2000, 2002) who claimed that the pods 125 have low content of CTs, but with exceptionally high biological activity. Silanikove et 
al. (2006) have demonstrated that the yield of CTs is considerably affected by the extraction method applied (from 5.0\% with acidic methanol to $17.2 \%$ with urea-buffer solution), suggesting that carob pods are a rich source of CTs. The high CT concentration in by-products from carob pod processing justifies researching its value 130 as a feed additive with possible effect against GIN species.

131 Sainfoin, which can be found especially in southern parts of Europe, has been the 132 subject of renewed interest because of its beneficial effects in the context of 133 agroecology (Hayot Carbonero et al., 2011), its beneficial impact on ruminant 134 production and the environment and its potential antiparasitic effects on small 135 ruminants (Manolaraki et al., 2010; Hoste et al., 2015; Saratsis et al., 2016; Mueller136 Harvey et. al., 2019). In vitro studies have shown that sainfoin extracts have a dose137 dependent effect against different GIN species (Brunet et al., 2007; Manolaraki et al., 138 2010; Novobilsky et al., 2013). Moreover, in vivo anthelmintic effects have also been 139 described in sheep and/or goats fed with sainfoin; i.e. $42-68 \%$ reduction in parasitic 140 egg excretion, which was associated with a $17.6 \%$ decrease in female worm fecundity 141 and a $45 \%$ decrease in worm numbers for Haemonchus contortus (Arroyo-Lopez et 142 al., 2014).

143 The present study, therefore, sought to explore the anthelmintic effects of feeding 144 regimes employing two CT-containing plant resources that may be relevant for 145 Mediterranean conditions. These were offered to lambs either alone or in combination 146 to evaluate their efficacies against two GIN species (H. contortus and 147 Trichostrongylus colubriformis). The specific objectives were to explore whether a) 148 the anthelmintic effect of carob in the feed is dose dependent (Trial 1), b) this 149 anthelmintic effect is associated with tannins by using polyethylene glycol (PEG) as a 
tannin-inhibitor (Trial 2), and c) there are any synergistic effects between carob and

151 sainfoin feeds (Trial 3).

152 2. Materials and Methods

$153 \quad$ 2.1. Stabling and animals

154 The experiments were carried out at the Asomaton Research Station of HAO Demeter

155 on the island of Crete, Greece. The animal barn was of an open-sided shed type, with

156 straw bedding. During the whole study the animals were kept indoors with each group

157 in a separate pen of approximately $10 \mathrm{~m}^{2}$ and $10 \mathrm{~m}^{2}$ open yard. The study included

158 three trials with lambs belonging to the local "Sfakion" breed. In order to achieve

159 uniformity of the experimental animals, all lambs included were female, 6-month-old

160 with a comparable body weight (BW), which was within the normal BW range of the

161 breed $(22-30 \mathrm{~kg})$ at the specific age. The lambs were raised indoors under helminth-

162 free conditions. Fourteen days before the start of each trial, they were drenched with

163 albendazole at the higher commercially recommended dose (ALBENDAZOLE

164 Drench, PROVET, $7.5 \mathrm{mg} / \mathrm{kg}$ ) and they tested negative by faecal egg counts at the

165 start of each trial. No anthelmintic resistance was previously recorded for this specific

166 flock.

\section{2.3. Infective larvae}

168 Third-stage infective larvae of $H$. contortus and $T$. colubriformis strains, susceptible

169 to all classes of anthelmintic drugs, had been cultured from faeces of mono-

170 specifically infected donor sheep. Larvae were recovered using the Baermann

171 technique and then stored for $1-2$ months at $4^{\circ} \mathrm{C}$ until use.

172

173

\subsection{Tannin-containing plant resources}


174 Carob pods (after removal of the seeds) were locally purchased and offered as crushed

175 flour meal incorporated in the concentrate feed supplement. Sainfoin pellets (Perly

176 cultivar, $3^{\text {rd }}$ cut) were provided by Multifolia (Viapres le Petit 10380, France) as part

177 of the Research project CARES.

\subsection{Tannin concentration and composition}

179 Tannin concentrations and compositions were determined in triplicate using two

180 different assays, i.e. the acetone-butanol- $\mathrm{HCl}$ assay and the thiolytic degradation with

181 benzyl mercaptan. Both techniques were applied in order to ensure a comprehensive

182 analysis since it was previously demonstrated that, depending on the types of CTs, the

183 acetone-HCl-butanol assay can give higher CT concentrations than the thiolysis assay.

184 The acetone-HCl-butanol assay was carried out as previously described by Grabber et 185 al. (2013) and Desrues et al. (2017).

186 The thiolysis reaction was carried out with benzyl mercaptan (Gea et al., 2011;

187 Ropiak et al., 2016), the reaction products were identified by HPLC-MS analysis

188 (Williams et al., 2014; Desrues et al., 2017) and quantified based on peak areas at 280

189 nm (Gea et al., 2011; Ropiak et al., 2016). This provided information on CT 190 concentration (g CT/100 g DW), CT size (in terms of mean degree of polymerisation,

$191 \mathrm{mDP}$ ), molar percentages of prodelphinidins (PD) and procyanidins (PC) within CTs,

192 and molar percentages of cis- vs trans- flavan-3-ol subunits (Ropiak et al., 2016).

\section{2.6. Experimental design}

194 All diets offered to the animals during the experimental period (with or without the 195 tannin sources) were formulated to meet the nutrient requirements of the animals 196 (NRC, 2007) and the total rations were always iso-nitrogenous and iso-energetic as 

access to clean water at all times. The animals' appetite was assessed and feed consumption (as feed offered minus refusals) was recorded on a daily basis by the

200 farm manager.

\subsubsection{Trial 1}

202 To determine the anthelmintic effect of carob pod meal and to define the optimal 203 concentration in a sheep ration, a subset of 35 lambs were randomly allocated to 5 204 groups ( $\mathrm{n}=7$ lambs/diet) (Table 1).

205 Carob meal (CaBP) was offered as feed supplement, at increasing rates of 0\%, 3\%, $2066 \%, 9 \%$ and $12 \%(\mathrm{~g} \mathrm{CaBP} / 100 \mathrm{~g} \mathrm{DM})$ of the total ration. The highest proportion, of 207 carob meal contributed to concentrate feed was set to $12 \%$ (due to its poor energy and 208 protein contents) in order to enable formulating a ration, which could cover the 209 nutritional requirements of lambs.

210 Feeding the experimental diets started 2 weeks prior (D14) to experimental infection 211 with nematode larvae (D0) in order for the animals to adapt to the feed.

212 On DAY 0, all lambs in groups (i) to (v) were infected with a single dose of 12.000 $2133^{\text {rd }}$ stage larvae (L3) of H. contortus and 12.000 L3 of T. colubriformis. At the end of 214 the experimental period (D49), all lambs were euthanised by injection of a massive 215 dose of pentobarbital (Dolethal $\left.{ }^{\circledR}\right)$.

\subsubsection{Trial 2}

217 Four groups of 6 lambs were included in a two-factorial trial (diet and PEG-addition).

218 Two groups were offered $\mathrm{CaBP}$ as feed supplement at the rate of $12 \%$ in the total 219 ration, and two groups remained on standard diet (Table 1). Half of the lambs in each 220 diet group were offered PEG (Polyethylene Glycol 4000, Fisher Scientific USA) 
221 orally (60 g/lamb diluted in $200 \mathrm{ml}$ water) on a daily basis after being allocated into 222 groups.

223 On D0, all lambs were experimentally infected with $8.000 \mathrm{~L} 3$ of $H$. contortus and

22416.000 L3 of T. colubriformis. On D21, after parasite infection was confirmed by 225 positive faecal examination, the animals were allocated into 4 groups of 6 lambs each, 226 according to the experimental diets. On D37 they were euthanised as described above.

\subsubsection{Trial 3}

228 To determine the possible synergistic anthelmintic effects between 2 CT-containing 229 resources namely carob (C. siliqua) and sainfoin (O. viciifolia), 4 groups of 6 lambs 230 were included in a two-factorial design (Table 1).

231 On D-14 each group of lambs received the allocated diet, containing i) carob meal 232 (CaBP) alone ii) sainfoin (S) pellets; iii) a combination of carob meal and sainfoin 233 pellets $(\mathrm{CaBP}+\mathrm{S})$ while iv) a control group $(\mathrm{C})$, received an isoproteic diet based on 234 lucerne. Carob was offered as a feed supplement at the rate of $12 \%$ in the total ration. 235 Sainfoin was offered as pellets representing 35\% of the total ration. On D0 all lambs 236 were infected with a single dose of $12.000 \mathrm{~L} 3$ of $H$. contortus and $12.000 \mathrm{~L} 3$ of $T$. 237 colubriformis. At the end of the experimental period (D37), all lambs were euthanised 238 as previously described.

\section{2.7. Pathophysiological parameters}

240 Individual blood samples were collected once weekly (from D0 to D49) during Trial 1 241 and once every two weeks (from D0 to D28) during Trial 3, by jugular venipuncture 242 into heparinized tubes (BD Vacutainer®, UK) to determine the packed cell volume 243 (PCV), as an indicator of anaemia, according to the micro-haematocrit method. In 
244 Trial 2 due to its short duration, the recording of PCV values was not included in the 245 design.

\subsection{Parasitological parameters}

247 Individual faecal samples were collected weekly directly from the rectum, during the

$2481^{\text {st }}$ and $3^{\text {rd }}$ trial, and twice weekly during the $2^{\text {nd }}$ trial in order to determine faecal egg 249 counts (FEC) using a modified McMaster technique (Roepstorff and Nansen, 1998).

250 FEC data were expressed as eggs per gram of faeces (EPG).

251 At necropsy, the abomasa and the first 12 meters of small intestine were separated, 252 ligated, rapidly removed and immediately processed to collect the adult worms from 253 the luminal contents. For the intra-mucosal larvae, pepsin digestion was applied both 254 on the abomasum and intestinal mucosa (MAFF, 1986). After $4 \mathrm{~h}$ incubation at $37^{\circ} \mathrm{C}$ 255 the larvae were collected. After storage in $10 \%$ alcohol, worm counts were performed 256 according to a $10 \%$ aliquot technique (MAFF, 1986). Morphological identification of 257 worm stages, sex and species were conducted using standard procedures (MAFF, 258 1986).

259 The fecundity of female worms was measured on 10 worms per lamb. For $T$. 260 colubriformis, eggs were counted directly in utero after clearing in $85 \%$ lactic acid 261 solution. All egg counts were performed under a microscope set at 10 times 262 magnification (total $100 \times$ ). For $H$. contortus, the fecundity was determined using the 263 method described by Kloostermann et al. (1978). Briefly, the worms were soaked for $2645 \mathrm{~min}$ in a large volume of distilled water, before being placed individually in 265 microtubes with $1000 \mu \mathrm{l}$ of $0.125 \%$ hypochlorite concentration solution and kept at 266 room temperature for 20 minutes. Treatment resulted in female worms disintegrating 267 thus enabling the direct counting of eggs under a stereo-microscope using an aliquot $268(10 \%)$ of the total volume. 


\subsection{Statistical analyses}

270 The data of FEC and adult worm counts (AWC) were $\log 10(\mathrm{x}+1)$ transformed prior to 271 analysis. For the FEC values, comparison of all groups was first performed using an 272 analysis of variance (ANOVA) with time as repeated measurement. Then, the 273 comparison of results to the control values were carried out date by date, using one274 way ANOVA completed by the post-hoc Bonferroni test for pairwise comparisons. 275 Group means of AWC were compared by one-way ANOVA (Trial 1) or two-way 276 ANOVA (Trial 2: $\mathrm{CaBP}+/-$ and PEG +/-; Trial 3: $\mathrm{CaBP}+/-$ and sainfoin +/-). 277 Regarding the fecundity of female worms, the Shapiro-Wilk Test of normality, which 278 is more appropriate for small sample sizes, was used. In cases where the data deviated 279 significantly $(\mathrm{P}<0.05)$ from a normal distribution (Trial 1 and 3 for both parasite 280 species and Trial 2 for T. colubriformis) the appropriate test to check the difference of 281 fecundity between the groups, which is the non-parametric test of Kruskal-Wallis, 282 was used. Where the dependent variable was normally distributed $(\mathrm{P}>0.05)$ the 283 parametric test of one-way ANOVA (H. contortus of Trial 2) was used. Additionally, 284 for the Trial 1, the model of linear regression was used, in order to be investigated if 285 there was a negative correlation between the variables "percentages of carob" and 286 "fecundity of female worms" for both parasite species (H. contortus and $T$. 287 colubriformis). Finally, the Tukey HSD test was used for data of trial 3, in order to 288 investigate statistically significant differences between groups.

289 All statistical analyses were performed using the SyStat SPSS 9.0 Software.

\subsection{Ethical considerations}

292 The study was carried out in compliance with the national animal welfare regulations. 293 All trials took place in a Research Station of the Veterinary Research Institute. The 
294 experimental protocol was approved by the responsible institutional committee (VRI

295 Committee for Approval of Experimental protocols as appointed at 26/5/2014, 296 Decision nr 972). Euthanasia was performed in a humane manner according to EU 297 regulations.

\section{Results}

300 The CT concentrations and compositions are presented in Table 2. The HBA assay 301 yielded similar CT concentrations for both plant materials, whereas the thiolysis assay 302 generated lower CT concentrations for the sainfoin pellets. The thiolysis assay 303 revealed that: i) both carob and sainfoin CTs consisted mainly of prodelphinidins, 30496.7 and 74.7 mole percentages, respectively; ii) carob CTs were highly galloylated 305 (i.e. $41.1 \%$ of flavan-3-ol subunits are galloylated), but sainfoin CTs did not contain 306 any esterified galloyl groups; iii) carob CTs were characterised by a relatively high 307 average molecular weight $(\mathrm{mDP}=31.1)$, whereas sainfoin $\mathrm{CT}$ s had an $\mathrm{mDP}$ value of $308 \quad 11.5$.

\subsection{Trial 1}

311 The results of Trial 1 are shown in Table 3 and Figure 1

312 The analyses of FEC, based on the ANOVA on Repeated Measures from D21 to D49, 313 showed an overall non-significant difference between groups, but significant 314 difference over time (between days of sampling). Meanwhile, the date-by-date 315 ANOVA of FEC showed no significant differences between groups, whatever the 316 date, as well as no dose effect. Reduction in FEC, up to $39.2 \%$ on DAY 49 as 317 compared to controls, was observed only for the group fed with the highest 318 concentration of carob meal. 
319 For $H$. contortus, the AWC declined in the groups receiving the highest concentration

320 of carob meal but this effect was not statistically significant $(\mathrm{P}=0.964)$. In contrast,

321 there was a declining trend $(\mathrm{P}<0.06)$ for the numbers of $T$. colubriformis with 322 increasing carob concentration.

323 The fecundity values showed significant differences (15.6\%-59.3\% lower than $3240 \% \mathrm{CaBP}$ respectively from the lowest to the highest $\mathrm{CaBP}$ concentration) between 325 groups for $H$. contortus demonstrating a dose dependent effect $(\mathrm{P}<0.05)$.

326 The Box plot (Figure 1b) for H. contortus fecundity suggests that worms from the $3270 \% \mathrm{CaBP}$ group tended to be more fecund than other CaBP groups and there may be 328 some degree of fecundity discrepancy between CaBP groups. This trend was 329 confirmed with the non-parametric test of Kruskal-Wallis, which showed that there 330 were statistically significant differences in fecundity between the groups $(\mathrm{P}<0.001)$. 331 More specifically, fecundity was statistically significantly greater for $0 \% \mathrm{CaBP}$ group 332 than the other CaBP groups. On the other hand, regarding T. colubriformis fecundity, 333 there was no statistically significant difference between the groups $(\mathrm{P}=0.128)$. 334 However, the model of linear regression, which was implemented and was 335 statistically significant $(\mathrm{P}<0.05)$, showed a negative correlation between the variables 336 "group" and "fecundity" for both parasite species.

337 No GIN larvae were recovered after pepsin digestion.

338 Mean PCV values $( \pm \mathrm{SD})$ for groups $0 \% \mathrm{CaBP}, 3 \% \mathrm{CaBP}, 6 \% \mathrm{CaBP}, 9 \% \mathrm{CaBP}$, and $33912 \% \mathrm{CaBP}$ on the last day of the trial were $25.29( \pm 5.96), 23.00( \pm 5.72), 21.00$ $340( \pm 6.32), 23.00( \pm 5.89)$ and $24.00( \pm 5.00)$ respectively. No significant differences were 341 found between the groups in PCV.

342 Average daily gain (ADG) as calculated for the whole trial duration for $0 \% \mathrm{CaBP}$, $3433 \% \mathrm{CaBP}, 6 \% \mathrm{CaBP}, 9 \% \mathrm{CaBP}$ and $12 \% \mathrm{CaBP}$ groups was (mean \pm s.d.) $69.2 \mathrm{~g}( \pm 31.0)$, 
$34461.5( \pm 36.1), 68.7( \pm 33.0), 74.8( \pm 37.5)$ and $64.4( \pm 32.9) \mathrm{g}$ respectively, which yielded

345 no significant differences between the groups.

\subsection{Trial 2}

347 The results of Trial 2 are presented in Table 4 and Figure 2.

348 The Repeated Measurements Analyses of FEC showed an overall statistical difference

$349(\mathrm{P}<0.001)$ between the 4 groups. The date-by-date ANOVA of FEC indicated that 350 differences were most prominent on DAY 29 (significant statistical differences, $351 \mathrm{P}<0.02$ ) and then on DAY 33 (trend, $\mathrm{P}<0.07$ ). Specifically, the values of the C, $352 \mathrm{C}+\mathrm{PEG}, \mathrm{CaBP}+\mathrm{PEG}$ groups were comparable throughout the trial, while the group 353 receiving only carob $(\mathrm{CaBP})$ showed consistently lower FEC starting from DAY 25 354 until the last day of the experiment. It was evident that the effect of carob on FEC was 355 nullified by PEG.

356 Results on AWC, showed reduction only for $H$. contortus $(\mathrm{P}<0.03)$ resulting in an 357 overall statistical difference between the 4 groups, since the lowest worm counts were 358 found for the CaBP group. Especially, for $H$. contortus, a reduction of approximately $35965 \%$ was observed in the carob group compared to the control. The AWC in the $360 \mathrm{CaBP}+\mathrm{PEG}$ group were similar to the other 2 control groups showing no reduction in 361 worm population. On the other hand, no effect of carob was observed on $T$. 362 colubriformis worm counts.

363 No effect of carob on female fecundity was also observed, irrespective of the parasite 364 species. Both control and carob groups showed comparable levels of female fecundity 365 for the two parasite species. The Box plot in Figure $2 b$ showed that the range of 366 fecundity of $H$. contortus for $\mathrm{CaBP}$ group was greater than for $\mathrm{C}, \mathrm{C}+\mathrm{PEG}$ and $367 \mathrm{CaBP}+\mathrm{PEG}$ groups and the interquartile range (middle $50 \%$ of the records) was lower 368 on the fecundity scale in the CaBP group than in the other groups. 
No GIN larvae were recovered after pepsin digestion.

370 The average daily gain (ADG) of lambs as calculated for the whole trial duration for

371 (C), (C+PEG), $(\mathrm{CaBP})$ and $(\mathrm{CaBP}+\mathrm{PEG})$ groups was 51.8( \pm 30.1$)( \pm$ s.d. $), 69.8( \pm 19.9)$, $37260.8( \pm 29.3)$ and $40.5( \pm 25.6) \mathrm{g}$, respectively, which resulted in no significant 373 differences between the groups.

\section{3.3.Trial 3}

375 The results of Trial 3 are shown in Table 5 and Figure 3.

376 The FEC values of all experimental groups remained at very low levels up to DAY

377 21. The overall repeated analyses based on 3 dates of the patent phase (DAY 21, 378 DAY 28, DAY 37) showed a trend for differences $(\mathrm{P}<0.07)$ between groups. The 379 results of the date-by-date ANOVA test did not show difference on DAY 21 and on 380 DAY 28, while on DAY 37, the values of FEC in groups $\mathrm{CaBP}+\mathrm{S}$ and $\mathrm{S}$ tended to be 381 reduced $(\mathrm{P}<0.06)$ compared to the two other groups. When compared to the control 382 values of FEC, the reductions in the 3 treated groups ranged from $44.6 \%$ to 383 approximately $86 \%$. These differences were mainly found for the sainfoin group (S) 384 and carob+sainfoin $(\mathrm{CaBP}+\mathrm{S})$ groups. As regards the AWCs, no significant 385 differences were observed neither in the number of $H$. contortus and T. colubriformis. 386 No GIN larvae were recovered after pepsin digestion.

387 The non-parametric test of Kruskal-Wallis showed that there were statistically 388 significant differences in fecundity between the groups $(\mathrm{P}<0.001)$. Specifically, the $\mathrm{C}$ 389 group presented the highest fecundity values, while the $\mathrm{CaBP}+\mathrm{S}$ group presented the 390 lowest ones for both parasite species. Tukey HSD test for $H$. contortus showed that 391 the $\mathrm{C}$ group differed significantly from $\mathrm{CaBP}, \mathrm{S}$ and $\mathrm{CaBP}+\mathrm{S}$, while for $T$. 392 colubriformis fecundity for $\mathrm{CaBP}$ group was also statistically different from $\mathrm{CaBP}+\mathrm{S}$ 393 (Figure 3b). 
394 When exploring the pathophysiological parameters (i.e. PCV), the analysis of 395 variance on repeated measures and also the date by date ANOVA did not show 396 significant differences between the groups. Specific values for mean PCV $( \pm \mathrm{SD})$ on 397 DAY 28 of the respective groups $\mathrm{C}, \mathrm{CaBP}, \mathrm{S}$ and $\mathrm{CaBP}+\mathrm{S}$ were $31.67( \pm 3.39), 33.00$ $398 \quad( \pm 4.86), 31.33( \pm 3.61)$ and $30.50( \pm 4.37)$.

399 The average daily gain (ADG) as calculated for the whole trial duration for (C), $400(\mathrm{CaBP}),(\mathrm{S})$ and $(\mathrm{CaBP}+\mathrm{S})$ groups was (mean \pm s.d.) $122.5( \pm 38.1), \quad 88.2( \pm 39.2)$, $401 \quad 104.6( \pm 11.9)$ and $124.8( \pm 39.7) \mathrm{g}$, respectively and there were no significant 402 differences between the groups.

\section{Discussion}

The literature contains several in vitro and in vivo studies, conducted on small 405 ruminants, which evaluated the anthelmintic effect of tannin-containing plants. Such studies first examined temperate forage legumes fed through grazing, as hay, silage or

407 pellets. Examples are sainfoin (Hoste et al., 2016; Legendre et al., 2018; Mueller408 Harvey et al., 2019), sericea lespedeza (Lespedeza cuneata) (Burke et al., 2012a,b; 409 Mechineni et al., 2014; Kommuru et al., 2014, 2015), and sulla (Hedysarum 410 coronarium) (Niezen et al., 1995, 2002). More recently, there has been also a growing 411 interest in tannin-containing by-products from the food industry as illustrated by 412 studies with hazelnut peels (Corylus avellana fruits) (Desrues et al., 2012; Girard et 413 al., 2013), carob pods (Manolaraki et al., 2010; Arroyo-Lopez et al., 2014) and 414 browse plants such as Pistacia lentiscus (Landau et al., 2010; Manolaraki et al., 415 2010), Quercus coccifera (Manolaraki et al., 2010) and Salix spp (Mupeyo et al., 416 2011). 
417 In the current study, we further explored the in vivo anthelmintic effects of carob pod 418 meal since it represents a common feed resource in the Mediterranean region and 419 there was some previous evidence of its anthelmintic (Arroyo-Lopez et al., 2014) and 420 anticoccidial (Saratsis et al., 2016; Legendre et al., 2018) properties. In order to 421 develop a practical implementation tool for carob as dietary intervention, we wanted 422 to identify a) the optimal carob concentration in the feed for bioactivity, b) whether 423 CTs contributed to such an activity and c) whether there were any synergistic effects 424 with other plant sources with different types of CTs (i.e. sainfoin). For all 3 trials a 425 balanced and palatable ration was specifically designed for all animals. This aimed to 426 achieve similar production indexes in all groups and ensured that any observed 427 differences in the effects of parasitism would not stem from quantitative differences in 428 the dietary composition but rather from differences in the bioactive CTs (Coop and 429 Kyriazakis, 1999; Athanasiadou et al., 2008; Hoste et al., 2015).

430 The parasites that served as models for this study (H. contortus and T. colubriformis) 431 are the most pathogenic and/or prevalent GIN species in European sheep and goats 432 (Charlier et al., 2018). These experiments allowed us to investigate carob-pods 433 efficacy against nematodes in the different anatomical location within the gut, as 434 location can affect the exposure of worms to different CT concentrations (Desrues et 435 al., 2017; Quijada et al., 2018).

436 Results of Trial 1 showed decreases in the mean values of FEC and AWC only in the 437 group fed with the highest concentration of $\mathrm{CaBP}$ in the concentrate feed, although 438 not significant. However, fecundity values showed a negative correlation to CaBP 439 concentration in the feed indicating a dose-dependent fecundity suppression effect. 440 The results suggest that carob used in feed at $12 \%$ has a potential anthelmintic effect 
441 and this effect is due mainly to the reduction of female worm fecundity 442 (predominantly in $H$. contortus) and to a lesser extent to the reduction of 443 establishment and development of the worms. Since $H$. contortus produce a 444 remarkably high daily egg output compared to T. colubriformis (Besier et al., 2016), 445 we suggest that the reduction in FEC seen in this trial can be attributed to the effect 446 the carob diet had against $H$. contortus. Overall, the results of this trial suggest that 447 the higher the concentration of carob in the ration the higher the anthelmintic activity; 448 this effect that was more evident for $H$. contortus. Unfortunately, there are limitations 449 to the quantity of carob pod meal that can be included in a well balanced ration since 450 carob pods contain high sugar but low protein and lipid concentrations (Priolo et al., 451 1998; Karabulut et al., 2006).

452 During Trial 2, the main results i) confirmed that CaBP reduced FEC in lambs, as 453 these reductions compared to control values ranged from $20 \%$ to $45 \%$, ii) that these 454 reductions in FEC seemed to be mainly due to the lower numbers from the highly 455 prolific $H$. contortus species and not from $T$. colubriformis, and that there were no 456 effects on female fecundity of both species and iii) that the anthelmintic effect of 457 CaBP may be attributed to CTs, because a restoration to control values for FEC and 458 Haemonchus worm numbers was observed in the CaBP + PEG group. PEG is a non459 nutritive synthetic polymer that is capable of binding and deactivating CTs; it has 460 been used in many animal nutrition studies to increase the intake of CT-containing 461 feeds and to improve protein absorption (Silanikove et al., 1996; Bermingham et al., 462 2001; Theodoridou et al., 2012). This ability has also been used to test (Brunet et al., 463 2007, 2008; Debela et al., 2012; Brito et al., 2018) whether any observed in vivo 464 anthelmintic activity was linked to the presence of CTs. 
465 Finally, the aim of Trial 3 was to investigate two hypotheses: firstly, that carob CTs 466 generate a stronger anthelmintic effect than sainfoin CTs and secondly, that 467 synergistic effects could be achieved by combining carob with sainfoin. The rationale 468 for these hypotheses is based on the fact that carob and sainfoin contain different 469 types of CTs and that these could target different stages of the GIN life cycle. Carob 470 CTs are highly galloylated prodelphinidins, whereas sainfoin CTs are non-galloylated 471 prodelphinidins. Previous studies found two structural features in CTs that enhance 472 anthelmintic activity in vitro: i) prodelphinidin CTs are more potent than procyanidin 473 CTs and ii) galloylation increases the anthelmintic effect of CTs (Hoste et al., 2016; 474 Kommuru et al., 2014, 2015). Therefore, carob CTs, which have a high 475 prodelphinidin/procyanidin ratio ( $96.7 \%$ prodelphinidins/3.3\% procyanidins) and are 476 also highly galloylated (i.e. $41.1 \%$ of the flavan-3-ol subunits are galloylated) should 477 produce a stronger anthelmintic effect than sainfoin, as sainfoin CTs have less 478 prodelphinidins $(74.8 \%)$ and no galloyl groups (N.B. \% stands for mole percent 479 within CT molecules; Table 2).

480 There are several important reasons that could explain why the results from Trial 3 481 did not support either of these hypotheses. Firstly, sainfoin - but not carob - was fed in 482 a pelleted form, while it has been demonstrated previously that the pelleting process 483 has a marked effect on CTs in terms of their analysis (Mueller-Harvey et al., 2019). 484 Table 2 shows that the CT concentrations in sainfoin pellets differed considerably 485 between the two assays (6.5 and $1.7 \mathrm{~g} \mathrm{CT} / 100 \mathrm{~g} \mathrm{DW})$ in contrast to the carob meal 486 data (5.8 and 7.2 g CT/100g DW). However, we currently do not know whether the 487 pelleting process enhances the anthelmintic activity of CTs or not. Secondly, up to 488 now most attempts to unravel links between CT structural features and anthelmintic 489 effects have employed in vitro assays. Therefore, in vivo feeding trials such as the 
present ones are vital to test the laboratory data. It may turn out that the esterified

491 galloyl groups are not stable in the digestive tract and that the prodelphinidins in

492 carob and sainfoin were the active CTs.

493 Therefore, preliminary conclusions from the Trial 3 data could be that galloylation is 494 unlikely to enhance anthelmintic activity in vivo in terms of $H$. contortus fecundity or 495 total worm counts and that pelleting of CT-plants might lead to lower FEC. These 496 indications will, however, need rigorous testing in the future.

497 The nutritional and/or anthelmintic properties of sainfoin fed as direct grazing, silage, 498 hay or pellets have been evaluated in both sheep and goats, with promising 499 anthelmintic results when used either alone (Paolini et al., 2005; Heckendorn et al., 500 2006; Ríos-de Alvarez et al., 2008; Gaudin et al., 2016) or in combination with other 501 CT sources (Girard et al., 2013). Previous results have demonstrated that sainfoin 502 consumption under different forms of preservation can reduce FEC and also reduce 503 female worm fecundity of $H$. contortus (Manolaraki et al., 2010; Arroyo-Lopez et al., 504 2014) or T. colubriformis (Manolaraki et al., 2010); however, in other studies a lack 505 of effect has been observed (Heckendorn et al., 2006). The issue of the variable 506 results has also been addressed in several reviews (Hoste et al., 2015; Hoste and 507 Niderkorn, 2019).

508 To summarise, the main results of trial 3 for FECs were i) a confirmation of 509 significant reductions of FEC due to the consumption of both $\mathrm{CaBP}$ and sainfoin 510 pellets; ii) a temporal increase in the anthelmintic effects of sainfoin but not for $\mathrm{CaBP}$, 511 and iii) no synergistic effects of the combination $\mathrm{CaBP}+$ sainfoin. In addition, it 512 would appear that these results can largely be explained by significant effects on 513 female fecundity of both species, but there were only limited effects on the worm 514 populations. No significant effects on AWC were observed for any of the species. On 
515 the other hand, although the differences were not significant, the percentage of 516 reduction compared to the controls (Group C) for $H$. contortus worm numbers were 517 respectively, for Groups CaBP $35.5 \%, \mathrm{~S} 62.1 \%$ and $\mathrm{CaBP}+\mathrm{S} 53.5 \%$.

518 In conclusion, the results of these three trials, which focussed on carob pod meal 519 alone or in combination, raised future research questions regarding what causes the 520 differences in results when different CT-containing resources are used and what is 521 required for a more rational use of CT-containing resources as nutraceutical feeds 522 under farm conditions and in different production systems (Hoste et al., 2015).

523 Our results confirmed that i) the consumption of CT containing resources can 524 modulate the biology of GINs; ii) that CT were involved in the anthelmintic effects of 525 carob and iii) the concentration in the diet influenced the anthelmintic effects as 526 previously shown in other in vivo studies with sericea lespedeza (Shaik et al., 2004, 527 2006) or sainfoin (Brunet et al., 2007) and iv) different mechanisms appeared to affect 528 the worm population and could explain the reduction of FECs: either a reduced 529 fecundity of female adult worms (see Trial 1 and 3) and /or a reduction of the number 530 of worms (see Trial 2).

531 The data of these 3 studies also illustrated that results depended on the type of 532 nematode species (abomasal or intestinal species) and/or on the nature of CT 533 resources (in our case carob vs sainfoin) and on the CTs. As stated by Quijada (2015) 534 and Desrues et al. (2016) the quantitative and qualitative differences in CTs appear to 535 influence the anthelmintic activity on the different species of parasitic nematodes.

537 Our results suggest that, when worm populations are exposed to CTs in the 538 gastrointestinal tract, upon their ingestion by the host the most evident effect recorded 539 is the reduction of female fecundity. Particularly for $H$. contortus, it appears that 
540 fecundity is only affected when the worms are exposed to CTs during maturation

541 (Trial 1 and 3) and not when they are already mature adults (Trial 2). On the other

542 hand, when CaBP was consumed for two weeks by animals in which adult worm

543 populations were already established and patent, the main finding was a significant

544 decrease in $H$. contortus worm counts. Moreover, the current study adds further

545 support to the observation that most of the CT effect is related to abomasal parasite -

546 and not so much to the small intestinal parasite. This is possibly due to the higher CT

547 concentration in the abomasum compared with the rumen and intestines, along with

548 higher prodelphinidin percentage as already shown in studies on the cattle abomasal

549 parasite Ostertagia ostertagi (Desrues et al., 2017).

\section{Acknowledgements}

551 This article is based upon work from EMIDA ERA-Net project CARES and COST

552 Action COMBAR CA16230 (European Cooperation in Science and Technology). The

553 authors would like to thank Chris Drake for the chemical analyses.

\section{References}

555 Arroyo-Lopez, C., Manolaraki, F., Saratsis, A., Saratsi, K., Stefanakis, A.,

556 Skampardonis, V., Voutzourakis, N., Hoste, H., Sotiraki, S., 2014. Anthelmintic

557 effect of carob pods and sainfoin hay when fed to lambs after experimental trickle

558 infections with Haemonchus contortus and Trichostrongylus colubriformis.

$559 \quad$ Parasite 21, 71. doi:10.1051/parasite/2014074

560 Athanasiadou, S., Houdijk, J., Kyriazakis, I., 2008. Exploiting synergisms and

561 interactions in the nutritional approaches to parasite control in sheep production 562 systems. Small Ruminant Res. 76, 2-11. 
563 Batlle, I., Tous, J., 1997. Carob tree Ceratonia siliqua L. Promoting the conservation 564 and use of underutilized and neglected crops 17, Institute of plant genetics and 565 crop plant research, Gatersleben/International Plant Genetics Resources Institute, $566 \quad$ Rome, Italy 23pp.

567 Bermingham, E.N., Hutchinson, K.J., Revell, D.K., Brookes, I.M., McNabb, W.C., 568 2001. The effect of condensed tannins in sainfoin (Onobrychis viciifolia) and sulla 569 (Hedysarum coronarium) on the digestion of amino acids in sheep. Proc. N.Z. Soc. $570 \quad$ Anim. Prod. 61, 116-119.

571 Besier, R.B., Kahn, L.P., Sargison, N.D., Van Wyk, J.A., 2016. Chapter four - The 572 pathophysiology, ecology and epidemiology of Haemonchus contortus infection in 573 small ruminants. In: Gasser, R., von Samson-Himmelstjerna, G. (Eds.), 574 Haemonchus contortus and Haemonchosis-Past, present and future trends. Adv $575 \quad$ Parasit. 93, 95-143.

576 Bravo, L., Grades, N., Saura-Calixto, F., 1994. Composition and potential uses of 577 mesquite pods (Prosopis pallida L.): Comparison with carob pods (Ceratonia 578 siliqua L.). J. Sci. Food Agr. 65, 303-306. doi:10.1002/jsfa.2740650307

579 Brito, D.R.B., Costa-Júnior, L.M., Garcia, J.L., Torres-Acosta, J.F.J., Louvandini, H., 580 Cutrim-Júnior, J.A.A., Araújo, J.F.M., Soares, E.D.S., 2018. Supplementation with 581 dry Mimosa caesalpiniifolia leaves can reduce the Haemonchus contortus worm 582 burden of goats. Vet. Parasitol. 252, 47-51.

583 Brunet, S., Aufrere, J., El Babili, F., Fouraste, I., Hoste, H., 2007. The kinetics of 584 exsheathment of infective nematode larvae is disturbed in the presence of tannin585 rich plant extract (sainfoin) both in vitro and in vivo. Parasitology 134, 1253-1262. 586 doi:10.1017/S0031182007002533 
Brunet, S., Martinez-Ortiz de Montellano, C., Torres-Acosta, J. F. J., Sandoval-

588 Castro, C. A., Aguilar-Caballero, A. J., Capetillo-Leal, C., Hoste, H., 2008. Effect

589 of the consumption of Lysiloma latisiliquum on the larval establishment of 590 gastrointestinal nematodes in goats. Vet. Parasitol. 157, 81-88. 591 doi:10.1016/j.vetpar.2008.07.013

592 Burke, J.M., Miller, J.E., Mosjidis, J.A., Terrill, T.H., 2012a. Grazing sericea 593 lespedeza for control of gastrointestinal nematodes in lambs. Vet. Parasitol. 186, $594 \quad 507-512$.

595 Burke, J.M., Miller, J.E., Mosjidis, J.A., Terrill, T.H., 2012b. Use of a mixed sericea 596 lespedeza and grass pasture system for control of gastrointestinal nematodes in 597 lambs and kids. Vet. Parasitol. 186, 328-336.

598 Charlier, J., Thamsborg, S.M., Bartley, D.J., Skuce, P.J., Kenyon, F., Geurden, T., 599 Hoste, H., Williams, A.R., Sotiraki, S., Höglund, J., Chartier, C., Geldhof, P., van 600 Dijk, J., Rinaldi, L., Morgan, E.R., von Samson-Himmelstjerna, G., Vercruysse, J., 601 Claerebout, E., 2018. Mind the gaps in research on the control of gastrointestinal 602 nematodes of farmed ruminants and pigs. Transbound. Emerg. Dis. 65, 217-234. 603 doi:10.1111/tbed.12707

604 Coop, R. L., Kyriazakis, I., 1999. Nutrition-parasite interaction. Vet. Parasitol. 84, 605 187-204. doi:10.1016/S0304-4017(99)00070-9.

606 Debela, E., Tolera, A., Eik, L.O., Salte, R., 2012. Condensed tannins from Sesbania 607 sesban and Desmodium intortum as a means of Haemonchus contortus control in 608 goats. Trop. Anim. Health Pro. 44, 1939-1944.

609 Desrues, O., Vargas-Magana, J., Manolaraki, F., Pardo, E., Girard, M., Mathieu, C., 610 Vilarem, G., Torres-Acosta, J.F.J., Sandoval-Castro, C.A., Jean, H., Sampedro, R., 611 Hoste, H., 2012. Can hazel-nut peels be used to control gastrointestinal nematodes 
612 in goats? In: Book of abstracts, XI International Conference on Goats. Gran 613 Canaria, Spain, September 2012, pp 44.

614 Desrues, O., Fryganas, C., Ropiak, H.M., Mueller-Harvey, I., Enemark, H.L., 615 Thamsborg, S.M., 2016. Impact of chemical structure of flavanol monomers and 616 condensed tannins on in vitro anthelmintic activity against bovine nematodes. 617 Parasitology 143, 444-454. doi:10.1017/S0031182015001912

618 Desrues, O., Mueller-Harvey, I., Pellikaan, W.F., Enemark, H.L., Thamsborg, S.M., 619 2017. Condensed tannins in the gastrointestinal tract of cattle after sainfoin 620 (Onobrychis viciifolia) intake and their possible relationship with anthelmintic 621 effects. J. Agric. Food Chem. 65, 1420-1427. doi:10.1021/acs.jafc.6b05830

622 Frutos, P., Moreno-Gonzalo, J., Hervas, G., García, U., Ferreira, L.M., Celaya, R., 623 Toral, P.G., Ortega-Mora, L.M., Ferre, I., Osoro, K., 2008. Is the anthelmintic 624 effect of heather supplementation to grazing goats always accompanied by anti625 nutritional effects? Animal 2, 1449-1456. doi:10.1017/S1751731108002681

626 Gaudin, E., Simon, M., Quijada, J., Schelcher, F., Sutra, G.F., Lespine, A., Hoste, H., 627 2016. Efficacy of sainfoin (Onobrychis viciifolia) pellets against multi resistant 628 Haemonchus contortus and interaction with oral ivermectin: Implications for on629 farm control. Vet. Parasitol. 227, 122-129.

630 Gea, A., Stringano, E., Brown, R.H., Mueller-Harvey, I., 2011. In situ analysis and 631 structural elucidation of sainfoin (Onobrychis viciifolia) tannins for high632 throughput germplasm screening. J. Agric. Food Chem. 59, 495-503.

633 Geurden, T., Hoste, H., Jacquiet, P., Traversa, D., Sotiraki, S., Frangipane di 634 Regalbono, A., Tzanidakis, N., Kostopoulou, D., Gaillac, C., Privat, S., 635 Giangaspero, A., Zanardello, C., Noé, L., Vanimisetti, B., Bartram D., 2014. 
636 Anthelmintic resistance and multidrug resistance in sheep gastro-intestinal 637 nematodes in France, Greece and Italy. Vet. Parasitol. 201, 59-66.

638 Girard, M., Gaid, S., Mathieu, C., Vilarem, G., Gerfault, V., Gombault, P., 639 Manolaraki, F., Hoste, H., 2013. Effects of different proportions of sainfoin pellets 640 combined with hazel nut peels on infected lambs. In: Book of abstracts of the $64^{\text {th }}$ 641 Annual Meeting of the European Federation of Animal Science. Nantes, 26-30th $642 \quad$ August 2013, pp.506

643 Grabber, J.H., Zeller, W.E., Mueller-Harvey, I., 2013. Acetone enhances the direct 644 analysis of procyanidin- and prodelphinidin-based condensed tannins in Lotus 645 species by the butanol-HCl-iron assay. J. Agric. Food Chem., 61, 2669-2678.

646 Hadjigeorgiou I., Osoro K., Fragoso de Almeida, J.P., Molle G., 2005. Southern 647 European grazing lands: production, environmental and landscape management 648 aspects. Livest. Prod. Sci., 96, 51-59.

649 Hayot Carbonero, C., Mueller-Harvey, I., Brown, T., Smith, L., 2011. Sainfoin 650 (Onobrychis viciifolia): A beneficial forage legume. Plant Genet. Resour-c. 9, 70$651 \quad$ 85. doi:10.1017/S1479262110000328

652 Heckendorn, F., Häring, D.A., Maurer, V., Zinsstag, J., Langhans, W., Hertzberg, H., 653 2006. Effect of sainfoin (Onobrychis viciifolia) silage and hay on established 654 populations of Haemonchus contortus and Cooperia curticei in lambs. Vet. 655 Parasitol. 142, 293-300.

656 Hoste, H., Torres-Acosta, J.F.J., 2011. Non chemical control of helminths in 657 ruminants adapting solutions for changing worms in a changing world. Vet. $658 \quad$ Parasitol. 180, 144-154.

659 Hoste, H., Torres-Acosta, J.F.J., Sandoval-Castro, C. A., Mueller-Harvey, I., Sotiraki, 660 S., Louvandini, H., Thamsborg, S.M., Terrill, T.H., 2015. Tannin containing 
661 legumes as a model for nutraceuticals against digestive parasites in livestock. Vet. 662 Parasitol. 212, 5-17.

663 Hoste, H., Niderkorn, V., 2019. Sainfoin and chicory: Using two model plants with 664 bioactive compounds to tackle agroecological challenges in ruminant livestock 665 farming. [Le sainfoin (Onobrychis viciifoliae) et la chicorée (Cichorium intybus): 666 Deux modèles de plantes bioactives pour répondre aux défis agroécologiques en 667 élevage de ruminants]. Fourrages 2019(238), 171-180.

668 Hoste, H., Torres-Acosta, J.F.J., Quijada, J., Chan-Perez, I., Dakheel, M.M., 669 Kommuru, D.S., Mueller-Harvey, I., Terrill, T.H., 2016. Chapter seven 670 Interactions between nutrition and infections with Haemonchus contortus and 671 related gastrointestinal nematodes in small ruminants. In: Gasser, R., von Samson672 Himmelstjerna, G. (Eds.), Haemonchus contortus and Haemonchosis-Past, present 673 and future trends. Adv. Parasit. 93, 239-351.

674 Jackson, F., 2000. Options for the sustainable control of gastrointestinal nematode 675 infections in goat production systems in Europe. In: Proceedings of the $7^{\text {th }}$ 676 International Conference on Goats, Tours, France, 15-21 May 2000, pp. 789-792. 677 Jackson, F., Varady, M., Bartley, D. J., 2012. Managing anthelmintic resistance in 678 goats - can we learn lessons from sheep? Small Ruminant Res. 103, 3-9.

679 Kaplan, R.M., 2020. Biology, Epidemiology, Diagnosis, and Management of 680 Anthelmintic Resistance in Gastrointestinal Nematodes of Livestock, Vet Clin N $681 \quad$ Am-Food A. 36 (1), 17-30, https://doi.org/10.1016/j.cvfa.2019.12.001.

682 Kaplan, R.M., Vidyashankar, A.N., 2012. An inconvenient truth: Global worming and 683 anthelmintic resistance. Vet. Parasitol. 186, 70-78. 
684 Karabulut, A., Canbolat, O., Kamalak, A., 2006. Evaluation of carob, Ceratonia 685 siliqua pods as a feed for sheep. Livestock Research for Rural Development 18, 686 Article \#104. http://www.lrrd.org/lrrd18/7/kara18104.htm

687 Keane, O. M., Keegan, J. D., Good, B., De Waal, T., Fanning, J., Gottstein, M., 688 Casey, M., Hurley, C., Sheehan, M., 2014. High level of treatment failure with 689 commonly used anthelmintics on Irish sheep farms, Irish Vet. J. 67, 16. 690 doi:10.1186/2046-0481-67-16

691 Kloosterman, A., Albers, G. A. A., Van Den Brink, R., 1978. Genetic variation 692 among calves in resistance to nematode parasites. Vet. Parasitol. 4, 353-368.

693 Kommuru, D.S., Barker, T., Desai, S., Burke, J.M., Ramsay, A., Mueller-Harvey, I., 694 Miller, J.E., Mosjidis, J.A., Kamisetti, N., Terrill, T.H., 2014. Use of pelleted 695 sericea lespedeza (Lespedeza cuneata) for natural control of coccidia and

697 Kommuru, D.S., Whitley, N.C., Miller, J.E., Mosjidis, J.A., Burke, J.M., Gujja, S., 698 Mechineni, A., Terrill, T.H., 2015. Effect of sericea lespedeza leaf meal pellets on 699 adult female Haemonchus contortus in goats. Vet. Parasitol. 207, 170-175.

700 Landau, S., Azaizeh, H., Muklada, H., Glasser, T., Ungar, E.D., Baram, H., Abbas, 701 N., Markovics, A., 2010. Anthelmintic activity of Pistacia lentiscus foliage in two 702 Middle Eastern breeds of goats differing in their propensity to consume tannin-rich 703 browse. Vet. Parasitol. 173, 280-286.

704 Legendre, H., Saratsi, K., Voutzourakis, N., Saratsis, A., Stefanakis, A., Gombault, P., 705 Hoste, H., Gidenne, T., Sotiraki, S., 2018. Coccidiostatic effects of tannin-rich 706 diets in rabbit production. Parasitol. Res. 117, 3705-3713. doi:10.1007/s00436$707 \quad 018-6069-2$ 
MAFF, 1986. Ministry of Agriculture, Fisheries and Food. Manual of Veterinary Parasitological Laboratory Techniques. Her Majesty’s Stationery Office, London, UK.

Manolaraki, F., Sotiraki, S., Stefanakis, A., Skampardonis, V., Volanis, M., Hoste, H., 2010. Anthelmintic activity of some Mediterranean browse plants against parasitic nematodes. Parasitology 137, 685-696. doi:10.1017/S0031182009991399

Marakis S., 1996. Carob bean in food and feed: current status and future potentials - a critical appraisal. J. Food Sci. Technol., 33, 365-383.

McKellar, Q.A., 1997. Ecotoxicology and residues of anthelmintic compounds. Vet. Parasitol. 72, 413-435.

Mechineni, A., Kommuru, D.S., Gujja, S., Mosjidis, J.A., Miller, J.E., Burke, J.M., Ramsay, A., Mueller-Harvey, I., Kannan, G., Lee, J.H., Kouakou, B., Terrill, T.H., 2014. Effect of fall-grazed sericea lespedeza (Lespedeza cuneata) on gastrointestinal nematode infections of growing goats. Vet. Parasitol. 204, 221228.

Méndez-Ortiz, F.A., Sandoval-Castro, C.A., Ventura-Cordero, J., Sarmiento-Franco, L.A., Torres-Acosta, J.F.J., 2018. Condensed tannin intake and sheep performance: A meta-analysis on voluntary intake and live weight change. Anim. Feed Sci. Tech. 245, 67-76.

Moreno-Gonzalo, J., Ferre, I., Celaya, R., Frutos, P., Ferreira, L.M.M., Hervás, G., García, U., Ortega-Mora, L.M., Osoro, K., 2012. Potential use of heather to control gastrointestinal nematodes in goats. Small Ruminant Res. 103, 60-68.

Moreno-Gonzalo, J., Manolaraki, F., Frutos, P., Hervas, G., Celaya, R., Osoro, K., Ortega-Mora, L.M., Hoste, H., Ferre, I., 2013a. In vitro effect of heather 
(Ericaceae) extracts on different stages of Teladorsagia circumcincta and Haemonchus contortus. Vet. Parasitol. 197, 235-243.

734 Moreno-Gonzalo, J., Manolaraki, F., Frutos, P., Hervas, G., Celaya, R., Osoro, K., 735 Ortega-Mora, L.M., Hoste, H., Ferre, I., 2013b. In vitro effect of heather extracts 736 on Trichostrongylus colubriformis eggs, larvae and adults. Vet. Parasitol. 197, 586737594.

738 Moreno-Gonzalo, J., Osoro, K., Garcia, U., Frutos, P., Celaya, R., Ferreira, L.M.M., 739 Ortega-Mora, L.M., Ferre, I., 2014. Anthelmintic effect of heather in goats 740 experimentally infected with Trichostrongylus colubriformis. Parasitol. Res. 113, $741 \quad 693-699$.

742 Morgan, E. R., Aziz, N. A., Blanchard, A., Charlier, J., Charvet, C., Claerebout, E., 743 Geldhof, P., Greer, A. W., Hertzberg, H., Hodgkinson, J., Höglund, J., Hoste, H., 744 Kaplan, R. M., Martínez-Valladares, M., Mitchell, S., Ploeger, H. W., Rinaldi, L., 745 von Samson-Himmelstjerna, G., Sotiraki, S., Schnyder, M., Skuce, P., Bartley, D., 746 Kenyon, F., Thamsborg, S.M., Rose Vineer, H., de Waal, T. Williams, A.R., van 747 Wyk J.A., Vercruysse, J. 2019. 100 Questions in Livestock Helminthology $748 \quad$ Research. Trends Parasitol., 35(1), 52-71.

749 Mueller-Harvey, I., 2006. Unravelling the conundrum of tannins in animal nutrition $750 \quad$ and health. J. Sci. Food Agr. 86, 2010-2037.

751 Mueller-Harvey, I., Bee, G., Dohme-Meier, F., Hoste, H., Karonen, M., Kolliker, R., 752 Lüscher, A., Niderkorn, V., Pellikaan, W.F., Salminen, J.P., Skot, L., Smith, 753 L.M.J., Thamsborg, S.M., Totterdell, P., Wilkinson, I., Williams, A.R., Azuhnwi, 754 B.N., Baert, N., Grosse Brinkhaus A., Copani, G., Desrues, O., Drake, C., 755 Engstrom, M., Fryganas, C., Girard, M., Huyen, N.T., Kempf, K., Malisch, C., 756 Mora-Ortiz, M., Quijada, J., Ramsay, A., Ropiak, H.M., Waghorn, G.C., 2019. 
Benefits of condensed tannins in forage legumes fed to ruminants: importance of structure, concentration and diet composition. Crop Sci. 59, 861-885.

759 Mupeyo, B., Barry, T.N., Pomroy, W.E., Ramírez-Restrepo, C. A., López-Villalobos, 760 N., Pernthaner, A., 2011. Effects of feeding willow (Salix spp.) upon death of 761 established parasites and parasite fecundity. Anim. Feed Sci. Tech. 164(1-2), 8-20.

762 Niezen, J.H., Waghorn, T.S., Charleston, W.A.G., Waghorn, G.C., 1995. Growth and 763 gastrointestinal nematode parasitism in lambs grazing either lucerne (Medicago 764 sativa) or sulla (Hedysarum coronarium) which contains condensed tannins. J. $765 \quad$ Agric. Sci 125, 281-289.

766 Niezen, J.H., Charleston, W.A.G., Robertson, H.A., Shelton, D., Waghorn, G.C., 767 Green, R., 2002. The effect of feeding sulla (Hedysarum coronarium) or lucerne 768 (Medicago sativa) on lamb parasite burdens and development of immunity to 769 gastrointestinal nematodes. Vet. Parasitol. 105, 229-245.

770 Novobilsky, A., Stringano, E., Hayot Carbonero, C., Smith, L.M.J., Enemark, H.L., 771 Mueller-Harvey, I., Thamsborg, S.M., 2013. In vitro effects of extracts and 772 purified tannins of sainfoin (Onobrychis viciifolia) against two cattle nematodes. $773 \quad$ Vet. Parasitol. 196, 532-537.

774 NRC (National Research Council) 2007 Nutrient Requirements of Small Ruminants: 775 Sheep, Goats, Cervids, and New World Camelids. Washington: The National 776 Academies Press.

777 Paolini, V., De La Farge, F., Prevot, F., Dorchies, P., Hoste, H., 2005. Effects of the 778 repeated distribution of sainfoin hay on the resistance and the resilience of goats 779 naturally infected with gastrointestinal nematodes. Vet. Parasitol. 127, 277-283.

780 Papachristou, T.G., Dziba, L.E., Provenza, F.D., 2005. Foraging ecology of goats and 781 sheep on wooded rangelands. Small Ruminant Res. 59, 141-156. 
Perry, B.D., Randolph, T.F., 1999. Improving the assessment of the economic impact of parasitic diseases and of their control in production animals. Vet. Parasitol. 84, 145-168.

Priolo, A., Lanza, M., Biondi, L., Pappalardo, P, Young, O.A., 1998. Effect of partially replacing dietary barley with $20 \%$ carob pulp on post- weaning growth, and carcass and meat characteristics of Comisana lambs. Meat Sci. 50, 355-363.

Priolo, A., Waghorn, G.C., Lanza, M., Biondi, L., Pennisi P., 2000. Polyethylene glycol as a means to reducing the impact of condensed tannins in carob pulp: effect on lamb growth and meat quality. J. Anim. Sci., 78, 810-816.

Priolo, A., Lanza, M., Bella, M., Pennisi, P., Fasone, V., Biondi, L., 2002. Reducing the impact of condensed tannins in a diet based on carob pulp using two levels of polyethylene glycol: lamb growth, digestion and meat quality Anim. Res., 51305 313.

Quijada, J., 2015. Relation structure/activité de tanins bioactifs contre les nématodes gastrointestinaux (Haemonchus contortus) parasites des petits ruminants. Doctorat de l'Université de Toulouse 235pp.

Quijada, J., Drake, C., Gaudin, E., El-Korso, R., Hoste, H., Mueller-Harvey, I., 2018. Condensed tannin changes along the digestive tract in lambs fed with sainfoin pellets or hazelnut skins. J. Agric. Food Chem. 66, 2136-2142.

Ropiak, H.M., Ramsay, A., Mueller-Harvey, I., 2016. Condensed tannins in extracts from European medicinal plants and herbal products. J. Pharmaceut. Biomed. 121, $225-231$.

Ríos-de Alvarez, L., Greer, A.W., Jackson, F., Athanasiadou, S., Kyriazakis, I., Huntley, J.F., 2008. The effect of dietary sainfoin (Onobrychis viciifolia) on local 

1117-1124.

808

809

Roepstorff, A., Nansen, P., 1998. Epidemiology Diagnosis and Control of helminth parasites of swine. FAO Animal Health Manual Rome, 51-56pp.

Saratsis, A., Voutzourakis, N., Theodosiou, T., Stefanakis, A., Sotiraki, S., 2016. The effect of sainfoin (Onobrychis viciifolia) and carob pods (Ceratonia siliqua) feeding regimes on the control of lamb coccidiosis Parasitol. Res. 115, 2233-2242. doi:10.1007/s00436-016-4966-9

Shaik, S.A., Terrill, T.H., Miller, J.E., Kouakou, B., Kannan, G., Kallu, R.K., Mosjidis, J.A., 2004. Effects of feeding sericea lespedeza hay to goats infected with Haemonchus contortus. S. Afr. J. Anim. Sci. 34, 248-250.

Shaik, S.A., Terrill, T.H., Miller, J.E., Kouakou, B., Kannan, G., Kaplan, R.M., Burke, J.M., Mosjidis, J.A., 2006. Sericea lespedeza hay as a natural deworming agent against gastrointestinal nematode infection in goats. Vet. Parasitol. 139, 150157.

Silanikove, N., Gilboa, N., Nir, I., Perevolotsky, A., Nitsan, Z., 1996. Effect of a daily supplementation of polyethylene glycol on intake and digestion of tannincontaining leaves (Quercus calliprinos, Pistacia lentiscus and Ceratonia siliqua) by goats. J. Agric. Food Chem. 44, 199-205.

Silanikove, N., Landau, S., Or, D., Kababya, D., Bruckental, I., Nitsan, Z., 2006. Analytical approach and effects of condensed tannins in carob pods (Ceratonia siliqua) on feed intake, digestive and metabolic responses of kids. Livest. Sci. 99, 29-38.

Silva Soares, S.C., de Lima, G.C., Laurentiz, A.C., Féboli, A., dos Anjos, L.A., de Paula Carlis, M.S., da Silva Filardi, R., da Silva de Laurentiza, R., 2018. In vitro 
anthelmintic activity of grape pomace extract against gastrointestinal nematodes of naturally infected sheep. Int. J. Vet. Sci. Med. 6, 243-247.

833 Stear, M.J., Doliglska, M., Donskow-Schmelter, K., 2007. Alternatives to 834 anthelmintics for the control of nematodes in livestock. Parasitology 134, 139-151. doi:10.1017/S0031182006001557

836 Terrill, T.H., Miller, J.E., Burke, J.M., Mosjidis, J.A., Kaplan, R.M., 2012.

837 Experiences with integrated concepts for the control of Haemonchus contortus in 838 sheep and goats in the United States. Vet. Parasitol. 186, 28-37.

839 Theodoridou, K., Aufrère, J., Andueza, D., Le Morvan, A., Picard, F., Pourrat, J., 840 Baumont, R., 2012. Effects of condensed tannins in wrapped silage bales of sainfoin 841 (Onobrychis viciifolia) on in vivo and in situ digestion in sheep. Animal 6, 245-253.

842 Torres-Acosta, J.F.J., Mendoza-de-Gives, P., Aguilar-Caballero, A.J., Cueíllar-Ordaz, 843 J.A., 2012. Anthelmintic resistance in sheep farms: update of the situation in the 844 American continent. Vet. Parasitol. 189, 89-96.

845 Waghorn, G., 2008. Beneficial and detrimental effects of dietary condensed tannins 846 for sustainable sheep and goat production-Progress and challenges. Anim. Feed $847 \quad$ Sci. Tech. $147,116-139$.

848 Waller, P.J., 2006. Sustainable nematode parasite control strategies for ruminant 849 livestock by grazing management and biological control. Anim. Feed Sci. Tech. $850 \quad 126,277-289$.

851 Williams, A.R., Fryganas, C., Ramsay, A., Mueller-Harvey, I., Thamsborg, S.M., 852 2014. Direct anthelmintic effects of condensed tannins from diverse plant sources 853 against Ascaris suum. PLoS ONE, 9(5), e97053. 854 doi:10.1371/journal.pone.0097053 
2 Feeding of carob (Ceratonia siliqua) to sheep infected with gastrointestinal nematodes

3 reduces faecal egg counts and worm fecundity

5 Katerina Saratsi ${ }^{\mathrm{a}, \mathrm{b}}$, Hervé Hoste ${ }^{\mathrm{c}, \mathrm{d}}$, Nikolaos Voutzourakis ${ }^{\mathrm{a}}$, Nikolaos Tzanidakis ${ }^{\mathrm{a}}$, 6 Alexandros Stefanakis ${ }^{\mathrm{a}}$, Stig Milan Thamsborg ${ }^{\mathrm{e}}$, Irene Mueller-Harvey ${ }^{\mathrm{f}}$, S., Ioannis Hadjigeorgiou $^{\mathrm{b}+}$, Smaragda Sotiraki ${ }^{\mathrm{a}+}$,

${ }^{\text {a } V e t e r i n a r y ~ R e s e a r c h ~ I n s t i t u t e, ~ H e l l e n i c ~ A g r i c u l t u r a l ~ O r g a n i z a t i o n-D e m e t e r, ~ T h e r m i ~}$

$11{ }^{\mathrm{b}}$ Department of Nutritional Physiology and Feeding, Faculty of Animal Science, Agricultural University of Athens, 11855 Athens, Greece

${ }^{\mathrm{c}}$ INRAE, UMR 1225 IHAP, 23 Chemin des Capelles, Toulouse F-31076, France

17 School of Agriculture, Policy and Development, University of Reading, P.O. Box 236,1 Earley Gate, Reading RG6 6AT, UK. 


\section{Abstract}

The present study explored the anthelmintic effects of condensed tannins (CT) in carob (Ceratonia siliqua) pods fed to sheep against gastrointestinal nematodes. Three independent in vivo trials tested whether i) carob pod (CaBP)-containing feed had an anthelmintic effect and if yes, which was the optimal concentration in the diet; ii) whether this effect could be attributed to tannins through the polyethylene glycol (PEG) test and iii) whether there were any synergistic effects when combined with another tannin-containing feed (e.g. sainfoin). In all trials 6-month old nematodenaive lambs, experimentally infected with both Haemonchus contortus and Trichostrongylus colubriformis, were used. Faecal egg counts (FEC) were performed regularly and at the end of each trial adult worm counts (AWC) and female worm fecundity were recorded. In trial 1, 35 lambs (five groups of seven lambs) were fed different $\mathrm{CaBP}$ concentrations ranging from $0 \%$ to $12 \% \mathrm{w} / \mathrm{w}$. FEC declined up to $39.2 \%$ only in the group fed with $12 \% \mathrm{CaBP}$, while a declining trend $(\mathrm{P}<0.06)$ was demonstrated for the AWC of T. colubriformis, which was associated with the increasing concentration of $\mathrm{CaBP}$ in feed. Female worm fecundity was reduced in groups fed $\mathrm{CaBP}$ for both parasites, however this was only significant for $H$. contortus $(\mathrm{P}<0.001)$, in a dose dependent manner. In trial 2 , four groups of six infected lambs each were used, which received the carob diets $\mathrm{CaBP}$ or $\mathrm{CaBP}+\mathrm{PEG}$, and the tannin-free diets with or without PEG (C or C+PEG). Results showed that FEC of Groups $\mathrm{C}, \mathrm{C}+\mathrm{PEG}$, and $\mathrm{CaBP}+\mathrm{PEG}$ were comparable throughout the trial, while the group receiving only CaBP showed lower FEC from DAY 25 onwards. AWC showed a reduction $(67.7 \%)$ only for $H$. contortus $(\mathrm{P}<0.03)$. Reversal of the anthelmintic effect of $\mathrm{CaBP}$ after PEG administration suggested that CT contributed to the anthelmintic action. However, no effect of CaBP was observed on $T$. 
51 colubriformis AWC and on female worm fecundity for both species. Finally, for trial

523 four groups of six lambs each received a diet based on $\mathrm{CaBP}$, sainfoin (S) or a 53 combination $(\mathrm{CaBP}+\mathrm{S})$ and were compared to a control (C) diet of lucerne. On DAY 5437 FEC values in groups $\mathrm{CaBP}+\mathrm{S}$ and $\mathrm{S}$ tended to be lower compared to the two other 55 groups $(\mathrm{C}, \mathrm{CaBP})$, while for AWCs no significant differences were observed for both 56 parasites. The fecundity of $H$. contortus and $T$. colubriformis demonstrated significant differences between the treated and control groups, with lower values in the animals receiving $\mathrm{CaBP}+\mathrm{S}$. Overall, the results supported the hypothesis that carob had an anthelmintic effect due to its $\mathrm{CT}$, but there was no clear indication of a synergistic effect with sainfoin.

61

Keywords: Carob, Sainfoin, Haemonchus contortus, Trichostrongylus colubriformis, 


\section{Introduction}

Infections by gastrointestinal nematodes (GIN) affect both health and welfare of grazing ruminants, causing anorexia, impaired digestion and nutrient absorption with related production losses, diarrhoea, anaemia and even death (Perry and Randolph, 1999; Stear et al., 2007; Hoste et al., 2016). Currently, the control of these parasites relies on repeated dosing with commercial anthelmintic drugs. However, the development of anthelmintic resistance in worm populations against one or multiple classes of anthelmintic has become a serious problem in several regions of the world, making it increasingly difficult to control parasitic infections (Kaplan, 2020). At the same time the increasing concerns of consumers about the presence of drug residues in foods and in the environment (McKellar, 1997) have stimulated the search for alternative or complementary solutions (Hoste and Torres-Acosta, 2011) within the context of organic farming and sustainable agriculture (Charlier et al., 2018).

91 Such alternatives include the use of bioactive plants with anthelmintic properties.

92 Many results indicate that such resources, because of the presence of plant secondary 93 metabolites (PSMs), might help to interfere with the biology of key-stages during 94 nematode cycle and to reduce the consequences of GIN infections in grazing 95 ruminants. Particular attention has been given to plants containing condensed tannins 96 (CT) and some related polyphenols (see reviews by Terrill et al., 2012; Hoste et al., 2015, 2016). Based on previous studies, the need to explore new plant resources to develop non-drug-based strategies for the integrated control of nematode parasites in

99 grazing ruminants has recently become a research priority in livestock production, 100 especially in ruminant breeding as also reviewed by Morgan et al, 2020. 
101 Small ruminants (sheep and goats) are a major component of the dairy sector in the

102 Mediterranean basin (Hadjigeorgiou et al., 2005). Sheep and goat production often

103 occupy marginal lands that are unsuitable for crop production but are rich in local

104 plants, such as rangeland vegetation, which can be exploited by animals as a feed

105 resource (Frutos et al., 2008; Méndez-Ortiz et al., 2018). Many rangeland plants also

106 contain PSMs, such as tannins (Papachristou et al., 2005) and several in vitro and in

107 vivo studies have evaluated their anthelmintic effects against GINs of small ruminants

108 (Manolaraki et al., 2010; Moreno-Gonzalo et al., 2012, 2013a,b, 2014; Arroyo-Lopez

109 et al., 2014; Silva Soares et al., 2018). Overall, CTs have been shown to directly or

110 indirectly interfere with the life cycle of several GINs and, therefore, CT-containing

111 plants, which also include many legumes, are proving to be beneficial nutritional

112 resources. However, a high degree of variability with respect to their anthelmintic

113 activity has also been recorded. Besides the total tannin concentration in ruminant

114 diets, recent studies have demonstrated that CT molecular composition or structural

115 characteristics can also affect anthelmintic activity (Mueller-Harvey et al., 2019).

116 Carob (Ceratonia siliqua) and sainfoin (Onobrychis viciifolia) are both resources of 117 the Fabaceae family and contain CTs. Carob is a leguminous tree that is widely 118 cultivated in the Mediterranean area. It is an important species both for economic and 119 environmental reasons (Batlle and Tous, 1997). Carob pods (fruits) are mostly used in 120 the food industry; pulp accounts for $90 \%$ by pod weight and seeds for $10 \%$. They 121 contain high sugar (48-56\%), but low protein (3-4\%) and lipid concentrations $(0.4-$ 122 0.8\%) (Marakis, 1996; Batlle and Tous, 1997). Moreover, ripe carob pods contain 123 high concentrations of CTs (16-20\% w/w DM) (Bravo et al., 1994; Batlle and Tous, 124 1997). This has been debated by Priolo et al. (2000, 2002) who claimed that the pods 125 have low content of CTs, but with exceptionally high biological activity. Silanikove et 
al. (2006) have demonstrated that the yield of CTs is considerably affected by the extraction method applied (from 5.0\% with acidic methanol to $17.2 \%$ with urea-buffer solution), suggesting that carob pods are a rich source of CTs. The high CT concentration in by-products from carob pod processing justifies researching its value 130 as a feed additive with possible effect against GIN species.

131 Sainfoin, which can be found especially in southern parts of Europe, has been the 132 subject of renewed interest because of its beneficial effects in the context of 133 agroecology (Hayot Carbonero et al., 2011), its beneficial impact on ruminant 134 production and the environment and its potential antiparasitic effects on small 135 ruminants (Manolaraki et al., 2010; Hoste et al., 2015; Saratsis et al., 2016; Mueller136 Harvey et. al., 2019). In vitro studies have shown that sainfoin extracts have a dose137 dependent effect against different GIN species (Brunet et al., 2007; Manolaraki et al., 138 2010; Novobilsky et al., 2013). Moreover, in vivo anthelmintic effects have also been 139 described in sheep and/or goats fed with sainfoin; i.e. $42-68 \%$ reduction in parasitic 140 egg excretion, which was associated with a $17.6 \%$ decrease in female worm fecundity 141 and a $45 \%$ decrease in worm numbers for Haemonchus contortus (Arroyo-Lopez et 142 al., 2014).

143 The present study, therefore, sought to explore the anthelmintic effects of feeding 144 regimes employing two CT-containing plant resources that may be relevant for 145 Mediterranean conditions. These were offered to lambs either alone or in combination 146 to evaluate their efficacies against two GIN species (H. contortus and 147 Trichostrongylus colubriformis). The specific objectives were to explore whether a) 148 the anthelmintic effect of carob in the feed is dose dependent (Trial 1), b) this 149 anthelmintic effect is associated with tannins by using polyethylene glycol (PEG) as a 
tannin-inhibitor (Trial 2), and c) there are any synergistic effects between carob and

151 sainfoin feeds (Trial 3).

152 2. Materials and Methods

$153 \quad$ 2.1. Stabling and animals

154 The experiments were carried out at the Asomaton Research Station of HAO Demeter

155 on the island of Crete, Greece. The animal barn was of an open-sided shed type, with

156 straw bedding. During the whole study the animals were kept indoors with each group

157 in a separate pen of approximately $10 \mathrm{~m}^{2}$ and $10 \mathrm{~m}^{2}$ open yard. The study included

158 three trials with lambs belonging to the local "Sfakion" breed. In order to achieve

159 uniformity of the experimental animals, all lambs included were female, 6-month-old

160 with a comparable body weight (BW), which was within the normal BW range of the

161 breed $(22-30 \mathrm{~kg})$ at the specific age. The lambs were raised indoors under helminth-

162 free conditions. Fourteen days before the start of each trial, they were drenched with

163 albendazole at the higher commercially recommended dose (ALBENDAZOLE

164 Drench, PROVET, $7.5 \mathrm{mg} / \mathrm{kg}$ ) and they tested negative by faecal egg counts at the

165 start of each trial. No anthelmintic resistance was previously recorded for this specific

166 flock.

\section{2.3. Infective larvae}

168 Third-stage infective larvae of $H$. contortus and $T$. colubriformis strains, susceptible

169 to all classes of anthelmintic drugs, had been cultured from faeces of mono-

170 specifically infected donor sheep. Larvae were recovered using the Baermann

171 technique and then stored for $1-2$ months at $4^{\circ} \mathrm{C}$ until use.

172

173

\subsection{Tannin-containing plant resources}


174 Carob pods (after removal of the seeds) were locally purchased and offered as crushed

175 flour meal incorporated in the concentrate feed supplement. Sainfoin pellets (Perly

176 cultivar, $3^{\text {rd }}$ cut) were provided by Multifolia (Viapres le Petit 10380, France) as part

177 of the Research project CARES.

\subsection{Tannin concentration and composition}

179 Tannin concentrations and compositions were determined in triplicate using two

180 different assays, i.e. the acetone-butanol- $\mathrm{HCl}$ assay and the thiolytic degradation with

181 benzyl mercaptan. Both techniques were applied in order to ensure a comprehensive

182 analysis since it was previously demonstrated that, depending on the types of CTs, the

183 acetone-HCl-butanol assay can give higher CT concentrations than the thiolysis assay.

184 The acetone-HCl-butanol assay was carried out as previously described by Grabber et 185 al. (2013) and Desrues et al. (2017).

186 The thiolysis reaction was carried out with benzyl mercaptan (Gea et al., 2011;

187 Ropiak et al., 2016), the reaction products were identified by HPLC-MS analysis

188 (Williams et al., 2014; Desrues et al., 2017) and quantified based on peak areas at 280

189 nm (Gea et al., 2011; Ropiak et al., 2016). This provided information on CT 190 concentration (g CT/100 g DW), CT size (in terms of mean degree of polymerisation,

$191 \mathrm{mDP}$ ), molar percentages of prodelphinidins (PD) and procyanidins (PC) within CTs,

192 and molar percentages of cis- vs trans- flavan-3-ol subunits (Ropiak et al., 2016).

\section{2.6. Experimental design}

194 All diets offered to the animals during the experimental period (with or without the 195 tannin sources) were formulated to meet the nutrient requirements of the animals 196 (NRC, 2007) and the total rations were always iso-nitrogenous and iso-energetic as 

access to clean water at all times. The animals' appetite was assessed and feed consumption (as feed offered minus refusals) was recorded on a daily basis by the

200 farm manager.

\subsubsection{Trial 1}

202 To determine the anthelmintic effect of carob pod meal and to define the optimal 203 concentration in a sheep ration, a subset of 35 lambs were randomly allocated to 5 204 groups ( $\mathrm{n}=7$ lambs/diet) (Table 1).

205 Carob meal (CaBP) was offered as feed supplement, at increasing rates of 0\%, 3\%, $2066 \%, 9 \%$ and $12 \%(\mathrm{~g} \mathrm{CaBP} / 100 \mathrm{~g} \mathrm{DM})$ of the total ration. The highest proportion, of 207 carob meal contributed to concentrate feed was set to $12 \%$ (due to its poor energy and 208 protein contents) in order to enable formulating a ration, which could cover the 209 nutritional requirements of lambs.

210 Feeding the experimental diets started 2 weeks prior (D14) to experimental infection 211 with nematode larvae (D0) in order for the animals to adapt to the feed.

212 On DAY 0, all lambs in groups (i) to (v) were infected with a single dose of 12.000 $2133^{\text {rd }}$ stage larvae (L3) of H. contortus and 12.000 L3 of T. colubriformis. At the end of 214 the experimental period (D49), all lambs were euthanised by injection of a massive 215 dose of pentobarbital (Dolethal $\left.{ }^{\circledR}\right)$.

\subsubsection{Trial 2}

217 Four groups of 6 lambs were included in a two-factorial trial (diet and PEG-addition).

218 Two groups were offered $\mathrm{CaBP}$ as feed supplement at the rate of $12 \%$ in the total 219 ration, and two groups remained on standard diet (Table 1). Half of the lambs in each 220 diet group were offered PEG (Polyethylene Glycol 4000, Fisher Scientific USA) 
221 orally (60 g/lamb diluted in $200 \mathrm{ml}$ water) on a daily basis after being allocated into 222 groups.

223 On D0, all lambs were experimentally infected with $8.000 \mathrm{~L} 3$ of $H$. contortus and

22416.000 L3 of T. colubriformis. On D21, after parasite infection was confirmed by 225 positive faecal examination, the animals were allocated into 4 groups of 6 lambs each, 226 according to the experimental diets. On D37 they were euthanised as described above.

\subsubsection{Trial 3}

228 To determine the possible synergistic anthelmintic effects between 2 CT-containing 229 resources namely carob (C. siliqua) and sainfoin (O. viciifolia), 4 groups of 6 lambs 230 were included in a two-factorial design (Table 1).

231 On D-14 each group of lambs received the allocated diet, containing i) carob meal 232 (CaBP) alone ii) sainfoin (S) pellets; iii) a combination of carob meal and sainfoin 233 pellets $(\mathrm{CaBP}+\mathrm{S})$ while iv) a control group $(\mathrm{C})$, received an isoproteic diet based on 234 lucerne. Carob was offered as a feed supplement at the rate of $12 \%$ in the total ration. 235 Sainfoin was offered as pellets representing 35\% of the total ration. On D0 all lambs 236 were infected with a single dose of $12.000 \mathrm{~L} 3$ of $H$. contortus and $12.000 \mathrm{~L} 3$ of $T$. 237 colubriformis. At the end of the experimental period (D37), all lambs were euthanised 238 as previously described.

\section{2.7. Pathophysiological parameters}

240 Individual blood samples were collected once weekly (from D0 to D49) during Trial 1 241 and once every two weeks (from D0 to D28) during Trial 3, by jugular venipuncture 242 into heparinized tubes (BD Vacutainer®, UK) to determine the packed cell volume 243 (PCV), as an indicator of anaemia, according to the micro-haematocrit method. In 
244 Trial 2 due to its short duration, the recording of PCV values was not included in the 245 design.

\subsection{Parasitological parameters}

247 Individual faecal samples were collected weekly directly from the rectum, during the

$2481^{\text {st }}$ and $3^{\text {rd }}$ trial, and twice weekly during the $2^{\text {nd }}$ trial in order to determine faecal egg 249 counts (FEC) using a modified McMaster technique (Roepstorff and Nansen, 1998).

250 FEC data were expressed as eggs per gram of faeces (EPG).

251 At necropsy, the abomasa and the first 12 meters of small intestine were separated, 252 ligated, rapidly removed and immediately processed to collect the adult worms from 253 the luminal contents. For the intra-mucosal larvae, pepsin digestion was applied both 254 on the abomasum and intestinal mucosa (MAFF, 1986). After $4 \mathrm{~h}$ incubation at $37^{\circ} \mathrm{C}$ 255 the larvae were collected. After storage in $10 \%$ alcohol, worm counts were performed 256 according to a $10 \%$ aliquot technique (MAFF, 1986). Morphological identification of 257 worm stages, sex and species were conducted using standard procedures (MAFF, 258 1986).

259 The fecundity of female worms was measured on 10 worms per lamb. For $T$. 260 colubriformis, eggs were counted directly in utero after clearing in $85 \%$ lactic acid 261 solution. All egg counts were performed under a microscope set at 10 times 262 magnification (total $100 \times$ ). For $H$. contortus, the fecundity was determined using the 263 method described by Kloostermann et al. (1978). Briefly, the worms were soaked for $2645 \mathrm{~min}$ in a large volume of distilled water, before being placed individually in 265 microtubes with $1000 \mu \mathrm{l}$ of $0.125 \%$ hypochlorite concentration solution and kept at 266 room temperature for 20 minutes. Treatment resulted in female worms disintegrating 267 thus enabling the direct counting of eggs under a stereo-microscope using an aliquot $268(10 \%)$ of the total volume. 


\subsection{Statistical analyses}

270 The data of FEC and adult worm counts (AWC) were $\log 10(\mathrm{x}+1)$ transformed prior to 271 analysis. For the FEC values, comparison of all groups was first performed using an 272 analysis of variance (ANOVA) with time as repeated measurement. Then, the 273 comparison of results to the control values were carried out date by date, using one274 way ANOVA completed by the post-hoc Bonferroni test for pairwise comparisons. 275 Group means of AWC were compared by one-way ANOVA (Trial 1) or two-way 276 ANOVA (Trial 2: $\mathrm{CaBP}+/-$ and PEG +/-; Trial 3: $\mathrm{CaBP}+/-$ and sainfoin +/-). 277 Regarding the fecundity of female worms, the Shapiro-Wilk Test of normality, which 278 is more appropriate for small sample sizes, was used. In cases where the data deviated 279 significantly $(\mathrm{P}<0.05)$ from a normal distribution (Trial 1 and 3 for both parasite 280 species and Trial 2 for T. colubriformis) the appropriate test to check the difference of 281 fecundity between the groups, which is the non-parametric test of Kruskal-Wallis, 282 was used. Where the dependent variable was normally distributed $(\mathrm{P}>0.05)$ the 283 parametric test of one-way ANOVA (H. contortus of Trial 2) was used. Additionally, 284 for the Trial 1, the model of linear regression was used, in order to be investigated if 285 there was a negative correlation between the variables "percentages of carob" and 286 "fecundity of female worms" for both parasite species (H. contortus and $T$. 287 colubriformis). Finally, the Tukey HSD test was used for data of trial 3, in order to 288 investigate statistically significant differences between groups.

289 All statistical analyses were performed using the SyStat SPSS 9.0 Software.

\subsection{Ethical considerations}

292 The study was carried out in compliance with the national animal welfare regulations. 293 All trials took place in a Research Station of the Veterinary Research Institute. The 
294 experimental protocol was approved by the responsible institutional committee (VRI

295 Committee for Approval of Experimental protocols as appointed at 26/5/2014, 296 Decision nr 972). Euthanasia was performed in a humane manner according to EU 297 regulations.

\section{Results}

300 The CT concentrations and compositions are presented in Table 2. The HBA assay 301 yielded similar CT concentrations for both plant materials, whereas the thiolysis assay 302 generated lower CT concentrations for the sainfoin pellets. The thiolysis assay 303 revealed that: i) both carob and sainfoin CTs consisted mainly of prodelphinidins, 30496.7 and 74.7 mole percentages, respectively; ii) carob CTs were highly galloylated 305 (i.e. $41.1 \%$ of flavan-3-ol subunits are galloylated), but sainfoin CTs did not contain 306 any esterified galloyl groups; iii) carob CTs were characterised by a relatively high 307 average molecular weight $(\mathrm{mDP}=31.1)$, whereas sainfoin $\mathrm{CT}$ s had an $\mathrm{mDP}$ value of $308 \quad 11.5$.

\subsection{Trial 1}

311 The results of Trial 1 are shown in Table 3 and Figure 1

312 The analyses of FEC, based on the ANOVA on Repeated Measures from D21 to D49, 313 showed an overall non-significant difference between groups, but significant 314 difference over time (between days of sampling). Meanwhile, the date-by-date 315 ANOVA of FEC showed no significant differences between groups, whatever the 316 date, as well as no dose effect. Reduction in FEC, up to $39.2 \%$ on DAY 49 as 317 compared to controls, was observed only for the group fed with the highest 318 concentration of carob meal. 
319 For $H$. contortus, the AWC declined in the groups receiving the highest concentration

320 of carob meal but this effect was not statistically significant $(\mathrm{P}=0.964)$. In contrast,

321 there was a declining trend $(\mathrm{P}<0.06)$ for the numbers of $T$. colubriformis with 322 increasing carob concentration.

323 The fecundity values showed significant differences (15.6\%-59.3\% lower than $3240 \% \mathrm{CaBP}$ respectively from the lowest to the highest $\mathrm{CaBP}$ concentration) between 325 groups for $H$. contortus demonstrating a dose dependent effect $(\mathrm{P}<0.05)$.

326 The Box plot (Figure 1b) for H. contortus fecundity suggests that worms from the $3270 \% \mathrm{CaBP}$ group tended to be more fecund than other CaBP groups and there may be 328 some degree of fecundity discrepancy between CaBP groups. This trend was 329 confirmed with the non-parametric test of Kruskal-Wallis, which showed that there 330 were statistically significant differences in fecundity between the groups $(\mathrm{P}<0.001)$. 331 More specifically, fecundity was statistically significantly greater for $0 \% \mathrm{CaBP}$ group 332 than the other CaBP groups. On the other hand, regarding T. colubriformis fecundity, 333 there was no statistically significant difference between the groups $(\mathrm{P}=0.128)$. 334 However, the model of linear regression, which was implemented and was 335 statistically significant $(\mathrm{P}<0.05)$, showed a negative correlation between the variables 336 "group" and "fecundity" for both parasite species.

337 No GIN larvae were recovered after pepsin digestion.

338 Mean PCV values $( \pm \mathrm{SD})$ for groups $0 \% \mathrm{CaBP}, 3 \% \mathrm{CaBP}, 6 \% \mathrm{CaBP}, 9 \% \mathrm{CaBP}$, and $33912 \% \mathrm{CaBP}$ on the last day of the trial were $25.29( \pm 5.96), 23.00( \pm 5.72), 21.00$ $340( \pm 6.32), 23.00( \pm 5.89)$ and $24.00( \pm 5.00)$ respectively. No significant differences were 341 found between the groups in PCV.

342 Average daily gain (ADG) as calculated for the whole trial duration for $0 \% \mathrm{CaBP}$, $3433 \% \mathrm{CaBP}, 6 \% \mathrm{CaBP}, 9 \% \mathrm{CaBP}$ and $12 \% \mathrm{CaBP}$ groups was (mean \pm s.d.) $69.2 \mathrm{~g}( \pm 31.0)$, 
$34461.5( \pm 36.1), 68.7( \pm 33.0), 74.8( \pm 37.5)$ and $64.4( \pm 32.9) \mathrm{g}$ respectively, which yielded

345 no significant differences between the groups.

\subsection{Trial 2}

347 The results of Trial 2 are presented in Table 4 and Figure 2.

348 The Repeated Measurements Analyses of FEC showed an overall statistical difference

$349(\mathrm{P}<0.001)$ between the 4 groups. The date-by-date ANOVA of FEC indicated that 350 differences were most prominent on DAY 29 (significant statistical differences, $351 \mathrm{P}<0.02$ ) and then on DAY 33 (trend, $\mathrm{P}<0.07$ ). Specifically, the values of the C, $352 \mathrm{C}+\mathrm{PEG}, \mathrm{CaBP}+\mathrm{PEG}$ groups were comparable throughout the trial, while the group 353 receiving only carob $(\mathrm{CaBP})$ showed consistently lower FEC starting from DAY 25 354 until the last day of the experiment. It was evident that the effect of carob on FEC was 355 nullified by PEG.

356 Results on AWC, showed reduction only for $H$. contortus $(\mathrm{P}<0.03)$ resulting in an 357 overall statistical difference between the 4 groups, since the lowest worm counts were 358 found for the CaBP group. Especially, for $H$. contortus, a reduction of approximately $35965 \%$ was observed in the carob group compared to the control. The AWC in the $360 \mathrm{CaBP}+\mathrm{PEG}$ group were similar to the other 2 control groups showing no reduction in 361 worm population. On the other hand, no effect of carob was observed on $T$. 362 colubriformis worm counts.

363 No effect of carob on female fecundity was also observed, irrespective of the parasite 364 species. Both control and carob groups showed comparable levels of female fecundity 365 for the two parasite species. The Box plot in Figure $2 b$ showed that the range of 366 fecundity of $H$. contortus for $\mathrm{CaBP}$ group was greater than for $\mathrm{C}, \mathrm{C}+\mathrm{PEG}$ and $367 \mathrm{CaBP}+\mathrm{PEG}$ groups and the interquartile range (middle $50 \%$ of the records) was lower 368 on the fecundity scale in the CaBP group than in the other groups. 
No GIN larvae were recovered after pepsin digestion.

370 The average daily gain (ADG) of lambs as calculated for the whole trial duration for

371 (C), (C+PEG), $(\mathrm{CaBP})$ and $(\mathrm{CaBP}+\mathrm{PEG})$ groups was 51.8( \pm 30.1$)( \pm$ s.d. $), 69.8( \pm 19.9)$, $37260.8( \pm 29.3)$ and $40.5( \pm 25.6) \mathrm{g}$, respectively, which resulted in no significant 373 differences between the groups.

\section{3.3.Trial 3}

375 The results of Trial 3 are shown in Table 5 and Figure 3.

376 The FEC values of all experimental groups remained at very low levels up to DAY

377 21. The overall repeated analyses based on 3 dates of the patent phase (DAY 21, 378 DAY 28, DAY 37) showed a trend for differences $(\mathrm{P}<0.07)$ between groups. The 379 results of the date-by-date ANOVA test did not show difference on DAY 21 and on 380 DAY 28, while on DAY 37, the values of FEC in groups $\mathrm{CaBP}+\mathrm{S}$ and $\mathrm{S}$ tended to be 381 reduced $(\mathrm{P}<0.06)$ compared to the two other groups. When compared to the control 382 values of FEC, the reductions in the 3 treated groups ranged from $44.6 \%$ to 383 approximately $86 \%$. These differences were mainly found for the sainfoin group (S) 384 and carob+sainfoin $(\mathrm{CaBP}+\mathrm{S})$ groups. As regards the AWCs, no significant 385 differences were observed neither in the number of $H$. contortus and T. colubriformis. 386 No GIN larvae were recovered after pepsin digestion.

387 The non-parametric test of Kruskal-Wallis showed that there were statistically 388 significant differences in fecundity between the groups $(\mathrm{P}<0.001)$. Specifically, the $\mathrm{C}$ 389 group presented the highest fecundity values, while the $\mathrm{CaBP}+\mathrm{S}$ group presented the 390 lowest ones for both parasite species. Tukey HSD test for $H$. contortus showed that 391 the $\mathrm{C}$ group differed significantly from $\mathrm{CaBP}, \mathrm{S}$ and $\mathrm{CaBP}+\mathrm{S}$, while for $T$. 392 colubriformis fecundity for $\mathrm{CaBP}$ group was also statistically different from $\mathrm{CaBP}+\mathrm{S}$ 393 (Figure 3b). 
394 When exploring the pathophysiological parameters (i.e. PCV), the analysis of 395 variance on repeated measures and also the date by date ANOVA did not show 396 significant differences between the groups. Specific values for mean PCV $( \pm \mathrm{SD})$ on 397 DAY 28 of the respective groups $\mathrm{C}, \mathrm{CaBP}, \mathrm{S}$ and $\mathrm{CaBP}+\mathrm{S}$ were $31.67( \pm 3.39), 33.00$ $398 \quad( \pm 4.86), 31.33( \pm 3.61)$ and $30.50( \pm 4.37)$.

399 The average daily gain (ADG) as calculated for the whole trial duration for (C), $400(\mathrm{CaBP}),(\mathrm{S})$ and $(\mathrm{CaBP}+\mathrm{S})$ groups was (mean \pm s.d.) $122.5( \pm 38.1), \quad 88.2( \pm 39.2)$, $401 \quad 104.6( \pm 11.9)$ and $124.8( \pm 39.7) \mathrm{g}$, respectively and there were no significant 402 differences between the groups.

\section{Discussion}

The literature contains several in vitro and in vivo studies, conducted on small 405 ruminants, which evaluated the anthelmintic effect of tannin-containing plants. Such studies first examined temperate forage legumes fed through grazing, as hay, silage or

407 pellets. Examples are sainfoin (Hoste et al., 2016; Legendre et al., 2018; Mueller408 Harvey et al., 2019), sericea lespedeza (Lespedeza cuneata) (Burke et al., 2012a,b; 409 Mechineni et al., 2014; Kommuru et al., 2014, 2015), and sulla (Hedysarum 410 coronarium) (Niezen et al., 1995, 2002). More recently, there has been also a growing 411 interest in tannin-containing by-products from the food industry as illustrated by 412 studies with hazelnut peels (Corylus avellana fruits) (Desrues et al., 2012; Girard et 413 al., 2013), carob pods (Manolaraki et al., 2010; Arroyo-Lopez et al., 2014) and 414 browse plants such as Pistacia lentiscus (Landau et al., 2010; Manolaraki et al., 415 2010), Quercus coccifera (Manolaraki et al., 2010) and Salix spp (Mupeyo et al., 416 2011). 
417 In the current study, we further explored the in vivo anthelmintic effects of carob pod 418 meal since it represents a common feed resource in the Mediterranean region and 419 there was some previous evidence of its anthelmintic (Arroyo-Lopez et al., 2014) and 420 anticoccidial (Saratsis et al., 2016; Legendre et al., 2018) properties. In order to 421 develop a practical implementation tool for carob as dietary intervention, we wanted 422 to identify a) the optimal carob concentration in the feed for bioactivity, b) whether 423 CTs contributed to such an activity and c) whether there were any synergistic effects 424 with other plant sources with different types of CTs (i.e. sainfoin). For all 3 trials a 425 balanced and palatable ration was specifically designed for all animals. This aimed to 426 achieve similar production indexes in all groups and ensured that any observed 427 differences in the effects of parasitism would not stem from quantitative differences in 428 the dietary composition but rather from differences in the bioactive CTs (Coop and 429 Kyriazakis, 1999; Athanasiadou et al., 2008; Hoste et al., 2015).

430 The parasites that served as models for this study (H. contortus and T. colubriformis) 431 are the most pathogenic and/or prevalent GIN species in European sheep and goats 432 (Charlier et al., 2018). These experiments allowed us to investigate carob-pods 433 efficacy against nematodes in the different anatomical location within the gut, as 434 location can affect the exposure of worms to different CT concentrations (Desrues et 435 al., 2017; Quijada et al., 2018).

436 Results of Trial 1 showed decreases in the mean values of FEC and AWC only in the 437 group fed with the highest concentration of $\mathrm{CaBP}$ in the concentrate feed, although 438 not significant. However, fecundity values showed a negative correlation to CaBP 439 concentration in the feed indicating a dose-dependent fecundity suppression effect. 440 The results suggest that carob used in feed at $12 \%$ has a potential anthelmintic effect 
441 and this effect is due mainly to the reduction of female worm fecundity 442 (predominantly in $H$. contortus) and to a lesser extent to the reduction of 443 establishment and development of the worms. Since $H$. contortus produce a 444 remarkably high daily egg output compared to T. colubriformis (Besier et al., 2016), 445 we suggest that the reduction in FEC seen in this trial can be attributed to the effect 446 the carob diet had against $H$. contortus. Overall, the results of this trial suggest that 447 the higher the concentration of carob in the ration the higher the anthelmintic activity; 448 this effect that was more evident for $H$. contortus. Unfortunately, there are limitations 449 to the quantity of carob pod meal that can be included in a well balanced ration since 450 carob pods contain high sugar but low protein and lipid concentrations (Priolo et al., 451 1998; Karabulut et al., 2006).

452 During Trial 2, the main results i) confirmed that CaBP reduced FEC in lambs, as 453 these reductions compared to control values ranged from $20 \%$ to $45 \%$, ii) that these 454 reductions in FEC seemed to be mainly due to the lower numbers from the highly 455 prolific $H$. contortus species and not from $T$. colubriformis, and that there were no 456 effects on female fecundity of both species and iii) that the anthelmintic effect of 457 CaBP may be attributed to CTs, because a restoration to control values for FEC and 458 Haemonchus worm numbers was observed in the CaBP + PEG group. PEG is a non459 nutritive synthetic polymer that is capable of binding and deactivating CTs; it has 460 been used in many animal nutrition studies to increase the intake of CT-containing 461 feeds and to improve protein absorption (Silanikove et al., 1996; Bermingham et al., 462 2001; Theodoridou et al., 2012). This ability has also been used to test (Brunet et al., 463 2007, 2008; Debela et al., 2012; Brito et al., 2018) whether any observed in vivo 464 anthelmintic activity was linked to the presence of CTs. 
465 Finally, the aim of Trial 3 was to investigate two hypotheses: firstly, that carob CTs 466 generate a stronger anthelmintic effect than sainfoin CTs and secondly, that 467 synergistic effects could be achieved by combining carob with sainfoin. The rationale 468 for these hypotheses is based on the fact that carob and sainfoin contain different 469 types of CTs and that these could target different stages of the GIN life cycle. Carob 470 CTs are highly galloylated prodelphinidins, whereas sainfoin CTs are non-galloylated 471 prodelphinidins. Previous studies found two structural features in CTs that enhance 472 anthelmintic activity in vitro: i) prodelphinidin CTs are more potent than procyanidin 473 CTs and ii) galloylation increases the anthelmintic effect of CTs (Hoste et al., 2016; 474 Kommuru et al., 2014, 2015). Therefore, carob CTs, which have a high 475 prodelphinidin/procyanidin ratio ( $96.7 \%$ prodelphinidins/3.3\% procyanidins) and are 476 also highly galloylated (i.e. $41.1 \%$ of the flavan-3-ol subunits are galloylated) should 477 produce a stronger anthelmintic effect than sainfoin, as sainfoin CTs have less 478 prodelphinidins $(74.8 \%)$ and no galloyl groups (N.B. \% stands for mole percent 479 within CT molecules; Table 2).

480 There are several important reasons that could explain why the results from Trial 3 481 did not support either of these hypotheses. Firstly, sainfoin - but not carob - was fed in 482 a pelleted form, while it has been demonstrated previously that the pelleting process 483 has a marked effect on CTs in terms of their analysis (Mueller-Harvey et al., 2019). 484 Table 2 shows that the CT concentrations in sainfoin pellets differed considerably 485 between the two assays (6.5 and $1.7 \mathrm{~g} \mathrm{CT} / 100 \mathrm{~g} \mathrm{DW})$ in contrast to the carob meal 486 data (5.8 and 7.2 g CT/100g DW). However, we currently do not know whether the 487 pelleting process enhances the anthelmintic activity of CTs or not. Secondly, up to 488 now most attempts to unravel links between CT structural features and anthelmintic 489 effects have employed in vitro assays. Therefore, in vivo feeding trials such as the 
present ones are vital to test the laboratory data. It may turn out that the esterified

491 galloyl groups are not stable in the digestive tract and that the prodelphinidins in

492 carob and sainfoin were the active CTs.

493 Therefore, preliminary conclusions from the Trial 3 data could be that galloylation is 494 unlikely to enhance anthelmintic activity in vivo in terms of $H$. contortus fecundity or 495 total worm counts and that pelleting of CT-plants might lead to lower FEC. These 496 indications will, however, need rigorous testing in the future.

497 The nutritional and/or anthelmintic properties of sainfoin fed as direct grazing, silage, 498 hay or pellets have been evaluated in both sheep and goats, with promising 499 anthelmintic results when used either alone (Paolini et al., 2005; Heckendorn et al., 500 2006; Ríos-de Alvarez et al., 2008; Gaudin et al., 2016) or in combination with other 501 CT sources (Girard et al., 2013). Previous results have demonstrated that sainfoin 502 consumption under different forms of preservation can reduce FEC and also reduce 503 female worm fecundity of $H$. contortus (Manolaraki et al., 2010; Arroyo-Lopez et al., 504 2014) or T. colubriformis (Manolaraki et al., 2010); however, in other studies a lack 505 of effect has been observed (Heckendorn et al., 2006). The issue of the variable 506 results has also been addressed in several reviews (Hoste et al., 2015; Hoste and 507 Niderkorn, 2019).

508 To summarise, the main results of trial 3 for FECs were i) a confirmation of 509 significant reductions of FEC due to the consumption of both $\mathrm{CaBP}$ and sainfoin 510 pellets; ii) a temporal increase in the anthelmintic effects of sainfoin but not for $\mathrm{CaBP}$, 511 and iii) no synergistic effects of the combination $\mathrm{CaBP}+$ sainfoin. In addition, it 512 would appear that these results can largely be explained by significant effects on 513 female fecundity of both species, but there were only limited effects on the worm 514 populations. No significant effects on AWC were observed for any of the species. On 
515 the other hand, although the differences were not significant, the percentage of 516 reduction compared to the controls (Group C) for $H$. contortus worm numbers were 517 respectively, for Groups CaBP $35.5 \%, \mathrm{~S} 62.1 \%$ and $\mathrm{CaBP}+\mathrm{S} 53.5 \%$.

518 In conclusion, the results of these three trials, which focussed on carob pod meal 519 alone or in combination, raised future research questions regarding what causes the 520 differences in results when different CT-containing resources are used and what is 521 required for a more rational use of CT-containing resources as nutraceutical feeds 522 under farm conditions and in different production systems (Hoste et al., 2015).

523 Our results confirmed that i) the consumption of CT containing resources can 524 modulate the biology of GINs; ii) that CT were involved in the anthelmintic effects of 525 carob and iii) the concentration in the diet influenced the anthelmintic effects as 526 previously shown in other in vivo studies with sericea lespedeza (Shaik et al., 2004, 527 2006) or sainfoin (Brunet et al., 2007) and iv) different mechanisms appeared to affect 528 the worm population and could explain the reduction of FECs: either a reduced 529 fecundity of female adult worms (see Trial 1 and 3) and /or a reduction of the number 530 of worms (see Trial 2).

531 The data of these 3 studies also illustrated that results depended on the type of 532 nematode species (abomasal or intestinal species) and/or on the nature of CT 533 resources (in our case carob vs sainfoin) and on the CTs. As stated by Quijada (2015) 534 and Desrues et al. (2016) the quantitative and qualitative differences in CTs appear to 535 influence the anthelmintic activity on the different species of parasitic nematodes.

537 Our results suggest that, when worm populations are exposed to CTs in the 538 gastrointestinal tract, upon their ingestion by the host the most evident effect recorded 539 is the reduction of female fecundity. Particularly for $H$. contortus, it appears that 
540 fecundity is only affected when the worms are exposed to CTs during maturation

541 (Trial 1 and 3) and not when they are already mature adults (Trial 2). On the other

542 hand, when CaBP was consumed for two weeks by animals in which adult worm

543 populations were already established and patent, the main finding was a significant

544 decrease in $H$. contortus worm counts. Moreover, the current study adds further

545 support to the observation that most of the CT effect is related to abomasal parasite -

546 and not so much to the small intestinal parasite. This is possibly due to the higher CT

547 concentration in the abomasum compared with the rumen and intestines, along with

548 higher prodelphinidin percentage as already shown in studies on the cattle abomasal

549 parasite Ostertagia ostertagi (Desrues et al., 2017).

\section{Acknowledgements}

551 This article is based upon work from EMIDA ERA-Net project CARES and COST

552 Action COMBAR CA16230 (European Cooperation in Science and Technology). The

553 authors would like to thank Chris Drake for the chemical analyses.

\section{References}

555 Arroyo-Lopez, C., Manolaraki, F., Saratsis, A., Saratsi, K., Stefanakis, A.,

556 Skampardonis, V., Voutzourakis, N., Hoste, H., Sotiraki, S., 2014. Anthelmintic

557 effect of carob pods and sainfoin hay when fed to lambs after experimental trickle

558 infections with Haemonchus contortus and Trichostrongylus colubriformis.

$559 \quad$ Parasite 21, 71. doi:10.1051/parasite/2014074

560 Athanasiadou, S., Houdijk, J., Kyriazakis, I., 2008. Exploiting synergisms and

561 interactions in the nutritional approaches to parasite control in sheep production 562 systems. Small Ruminant Res. 76, 2-11. 
563 Batlle, I., Tous, J., 1997. Carob tree Ceratonia siliqua L. Promoting the conservation 564 and use of underutilized and neglected crops 17, Institute of plant genetics and 565 crop plant research, Gatersleben/International Plant Genetics Resources Institute, $566 \quad$ Rome, Italy 23pp.

567 Bermingham, E.N., Hutchinson, K.J., Revell, D.K., Brookes, I.M., McNabb, W.C., 568 2001. The effect of condensed tannins in sainfoin (Onobrychis viciifolia) and sulla 569 (Hedysarum coronarium) on the digestion of amino acids in sheep. Proc. N.Z. Soc. $570 \quad$ Anim. Prod. 61, 116-119.

571 Besier, R.B., Kahn, L.P., Sargison, N.D., Van Wyk, J.A., 2016. Chapter four - The 572 pathophysiology, ecology and epidemiology of Haemonchus contortus infection in 573 small ruminants. In: Gasser, R., von Samson-Himmelstjerna, G. (Eds.), 574 Haemonchus contortus and Haemonchosis-Past, present and future trends. Adv $575 \quad$ Parasit. 93, 95-143.

576 Bravo, L., Grades, N., Saura-Calixto, F., 1994. Composition and potential uses of 577 mesquite pods (Prosopis pallida L.): Comparison with carob pods (Ceratonia 578 siliqua L.). J. Sci. Food Agr. 65, 303-306. doi:10.1002/jsfa.2740650307

579 Brito, D.R.B., Costa-Júnior, L.M., Garcia, J.L., Torres-Acosta, J.F.J., Louvandini, H., 580 Cutrim-Júnior, J.A.A., Araújo, J.F.M., Soares, E.D.S., 2018. Supplementation with 581 dry Mimosa caesalpiniifolia leaves can reduce the Haemonchus contortus worm 582 burden of goats. Vet. Parasitol. 252, 47-51.

583 Brunet, S., Aufrere, J., El Babili, F., Fouraste, I., Hoste, H., 2007. The kinetics of 584 exsheathment of infective nematode larvae is disturbed in the presence of tannin585 rich plant extract (sainfoin) both in vitro and in vivo. Parasitology 134, 1253-1262. 586 doi:10.1017/S0031182007002533 
Brunet, S., Martinez-Ortiz de Montellano, C., Torres-Acosta, J. F. J., Sandoval-

588 Castro, C. A., Aguilar-Caballero, A. J., Capetillo-Leal, C., Hoste, H., 2008. Effect

589 of the consumption of Lysiloma latisiliquum on the larval establishment of 590 gastrointestinal nematodes in goats. Vet. Parasitol. 157, 81-88. 591 doi:10.1016/j.vetpar.2008.07.013

592 Burke, J.M., Miller, J.E., Mosjidis, J.A., Terrill, T.H., 2012a. Grazing sericea 593 lespedeza for control of gastrointestinal nematodes in lambs. Vet. Parasitol. 186, $594 \quad 507-512$.

595 Burke, J.M., Miller, J.E., Mosjidis, J.A., Terrill, T.H., 2012b. Use of a mixed sericea 596 lespedeza and grass pasture system for control of gastrointestinal nematodes in 597 lambs and kids. Vet. Parasitol. 186, 328-336.

598 Charlier, J., Thamsborg, S.M., Bartley, D.J., Skuce, P.J., Kenyon, F., Geurden, T., 599 Hoste, H., Williams, A.R., Sotiraki, S., Höglund, J., Chartier, C., Geldhof, P., van 600 Dijk, J., Rinaldi, L., Morgan, E.R., von Samson-Himmelstjerna, G., Vercruysse, J., 601 Claerebout, E., 2018. Mind the gaps in research on the control of gastrointestinal 602 nematodes of farmed ruminants and pigs. Transbound. Emerg. Dis. 65, 217-234. 603 doi:10.1111/tbed.12707

604 Coop, R. L., Kyriazakis, I., 1999. Nutrition-parasite interaction. Vet. Parasitol. 84, 605 187-204. doi:10.1016/S0304-4017(99)00070-9.

606 Debela, E., Tolera, A., Eik, L.O., Salte, R., 2012. Condensed tannins from Sesbania 607 sesban and Desmodium intortum as a means of Haemonchus contortus control in 608 goats. Trop. Anim. Health Pro. 44, 1939-1944.

609 Desrues, O., Vargas-Magana, J., Manolaraki, F., Pardo, E., Girard, M., Mathieu, C., 610 Vilarem, G., Torres-Acosta, J.F.J., Sandoval-Castro, C.A., Jean, H., Sampedro, R., 611 Hoste, H., 2012. Can hazel-nut peels be used to control gastrointestinal nematodes 
612 in goats? In: Book of abstracts, XI International Conference on Goats. Gran 613 Canaria, Spain, September 2012, pp 44.

614 Desrues, O., Fryganas, C., Ropiak, H.M., Mueller-Harvey, I., Enemark, H.L., 615 Thamsborg, S.M., 2016. Impact of chemical structure of flavanol monomers and 616 condensed tannins on in vitro anthelmintic activity against bovine nematodes. 617 Parasitology 143, 444-454. doi:10.1017/S0031182015001912

618 Desrues, O., Mueller-Harvey, I., Pellikaan, W.F., Enemark, H.L., Thamsborg, S.M., 619 2017. Condensed tannins in the gastrointestinal tract of cattle after sainfoin 620 (Onobrychis viciifolia) intake and their possible relationship with anthelmintic 621 effects. J. Agric. Food Chem. 65, 1420-1427. doi:10.1021/acs.jafc.6b05830

622 Frutos, P., Moreno-Gonzalo, J., Hervas, G., García, U., Ferreira, L.M., Celaya, R., 623 Toral, P.G., Ortega-Mora, L.M., Ferre, I., Osoro, K., 2008. Is the anthelmintic 624 effect of heather supplementation to grazing goats always accompanied by anti625 nutritional effects? Animal 2, 1449-1456. doi:10.1017/S1751731108002681

626 Gaudin, E., Simon, M., Quijada, J., Schelcher, F., Sutra, G.F., Lespine, A., Hoste, H., 627 2016. Efficacy of sainfoin (Onobrychis viciifolia) pellets against multi resistant 628 Haemonchus contortus and interaction with oral ivermectin: Implications for on629 farm control. Vet. Parasitol. 227, 122-129.

630 Gea, A., Stringano, E., Brown, R.H., Mueller-Harvey, I., 2011. In situ analysis and 631 structural elucidation of sainfoin (Onobrychis viciifolia) tannins for high632 throughput germplasm screening. J. Agric. Food Chem. 59, 495-503.

633 Geurden, T., Hoste, H., Jacquiet, P., Traversa, D., Sotiraki, S., Frangipane di 634 Regalbono, A., Tzanidakis, N., Kostopoulou, D., Gaillac, C., Privat, S., 635 Giangaspero, A., Zanardello, C., Noé, L., Vanimisetti, B., Bartram D., 2014. 
636 Anthelmintic resistance and multidrug resistance in sheep gastro-intestinal 637 nematodes in France, Greece and Italy. Vet. Parasitol. 201, 59-66.

638 Girard, M., Gaid, S., Mathieu, C., Vilarem, G., Gerfault, V., Gombault, P., 639 Manolaraki, F., Hoste, H., 2013. Effects of different proportions of sainfoin pellets 640 combined with hazel nut peels on infected lambs. In: Book of abstracts of the $64^{\text {th }}$ 641 Annual Meeting of the European Federation of Animal Science. Nantes, 26-30th $642 \quad$ August 2013, pp.506

643 Grabber, J.H., Zeller, W.E., Mueller-Harvey, I., 2013. Acetone enhances the direct 644 analysis of procyanidin- and prodelphinidin-based condensed tannins in Lotus 645 species by the butanol-HCl-iron assay. J. Agric. Food Chem., 61, 2669-2678.

646 Hadjigeorgiou I., Osoro K., Fragoso de Almeida, J.P., Molle G., 2005. Southern 647 European grazing lands: production, environmental and landscape management 648 aspects. Livest. Prod. Sci., 96, 51-59.

649 Hayot Carbonero, C., Mueller-Harvey, I., Brown, T., Smith, L., 2011. Sainfoin 650 (Onobrychis viciifolia): A beneficial forage legume. Plant Genet. Resour-c. 9, 70$651 \quad$ 85. doi:10.1017/S1479262110000328

652 Heckendorn, F., Häring, D.A., Maurer, V., Zinsstag, J., Langhans, W., Hertzberg, H., 653 2006. Effect of sainfoin (Onobrychis viciifolia) silage and hay on established 654 populations of Haemonchus contortus and Cooperia curticei in lambs. Vet. 655 Parasitol. 142, 293-300.

656 Hoste, H., Torres-Acosta, J.F.J., 2011. Non chemical control of helminths in 657 ruminants adapting solutions for changing worms in a changing world. Vet. $658 \quad$ Parasitol. 180, 144-154.

659 Hoste, H., Torres-Acosta, J.F.J., Sandoval-Castro, C. A., Mueller-Harvey, I., Sotiraki, 660 S., Louvandini, H., Thamsborg, S.M., Terrill, T.H., 2015. Tannin containing 
661 legumes as a model for nutraceuticals against digestive parasites in livestock. Vet. 662 Parasitol. 212, 5-17.

663 Hoste, H., Niderkorn, V., 2019. Sainfoin and chicory: Using two model plants with 664 bioactive compounds to tackle agroecological challenges in ruminant livestock 665 farming. [Le sainfoin (Onobrychis viciifoliae) et la chicorée (Cichorium intybus): 666 Deux modèles de plantes bioactives pour répondre aux défis agroécologiques en 667 élevage de ruminants]. Fourrages 2019(238), 171-180.

668 Hoste, H., Torres-Acosta, J.F.J., Quijada, J., Chan-Perez, I., Dakheel, M.M., 669 Kommuru, D.S., Mueller-Harvey, I., Terrill, T.H., 2016. Chapter seven 670 Interactions between nutrition and infections with Haemonchus contortus and 671 related gastrointestinal nematodes in small ruminants. In: Gasser, R., von Samson672 Himmelstjerna, G. (Eds.), Haemonchus contortus and Haemonchosis-Past, present 673 and future trends. Adv. Parasit. 93, 239-351.

674 Jackson, F., 2000. Options for the sustainable control of gastrointestinal nematode 675 infections in goat production systems in Europe. In: Proceedings of the $7^{\text {th }}$ 676 International Conference on Goats, Tours, France, 15-21 May 2000, pp. 789-792. 677 Jackson, F., Varady, M., Bartley, D. J., 2012. Managing anthelmintic resistance in 678 goats - can we learn lessons from sheep? Small Ruminant Res. 103, 3-9.

679 Kaplan, R.M., 2020. Biology, Epidemiology, Diagnosis, and Management of 680 Anthelmintic Resistance in Gastrointestinal Nematodes of Livestock, Vet Clin N $681 \quad$ Am-Food A. 36 (1), 17-30, https://doi.org/10.1016/j.cvfa.2019.12.001.

682 Kaplan, R.M., Vidyashankar, A.N., 2012. An inconvenient truth: Global worming and 683 anthelmintic resistance. Vet. Parasitol. 186, 70-78. 
684 Karabulut, A., Canbolat, O., Kamalak, A., 2006. Evaluation of carob, Ceratonia 685 siliqua pods as a feed for sheep. Livestock Research for Rural Development 18, 686 Article \#104. http://www.lrrd.org/lrrd18/7/kara18104.htm

687 Keane, O. M., Keegan, J. D., Good, B., De Waal, T., Fanning, J., Gottstein, M., 688 Casey, M., Hurley, C., Sheehan, M., 2014. High level of treatment failure with 689 commonly used anthelmintics on Irish sheep farms, Irish Vet. J. 67, 16. 690 doi:10.1186/2046-0481-67-16

691 Kloosterman, A., Albers, G. A. A., Van Den Brink, R., 1978. Genetic variation 692 among calves in resistance to nematode parasites. Vet. Parasitol. 4, 353-368.

693 Kommuru, D.S., Barker, T., Desai, S., Burke, J.M., Ramsay, A., Mueller-Harvey, I., 694 Miller, J.E., Mosjidis, J.A., Kamisetti, N., Terrill, T.H., 2014. Use of pelleted 695 sericea lespedeza (Lespedeza cuneata) for natural control of coccidia and

697 Kommuru, D.S., Whitley, N.C., Miller, J.E., Mosjidis, J.A., Burke, J.M., Gujja, S., 698 Mechineni, A., Terrill, T.H., 2015. Effect of sericea lespedeza leaf meal pellets on 699 adult female Haemonchus contortus in goats. Vet. Parasitol. 207, 170-175.

700 Landau, S., Azaizeh, H., Muklada, H., Glasser, T., Ungar, E.D., Baram, H., Abbas, 701 N., Markovics, A., 2010. Anthelmintic activity of Pistacia lentiscus foliage in two 702 Middle Eastern breeds of goats differing in their propensity to consume tannin-rich 703 browse. Vet. Parasitol. 173, 280-286.

704 Legendre, H., Saratsi, K., Voutzourakis, N., Saratsis, A., Stefanakis, A., Gombault, P., 705 Hoste, H., Gidenne, T., Sotiraki, S., 2018. Coccidiostatic effects of tannin-rich 706 diets in rabbit production. Parasitol. Res. 117, 3705-3713. doi:10.1007/s00436$707 \quad 018-6069-2$ 
MAFF, 1986. Ministry of Agriculture, Fisheries and Food. Manual of Veterinary Parasitological Laboratory Techniques. Her Majesty’s Stationery Office, London, UK.

Manolaraki, F., Sotiraki, S., Stefanakis, A., Skampardonis, V., Volanis, M., Hoste, H., 2010. Anthelmintic activity of some Mediterranean browse plants against parasitic nematodes. Parasitology 137, 685-696. doi:10.1017/S0031182009991399

Marakis S., 1996. Carob bean in food and feed: current status and future potentials - a critical appraisal. J. Food Sci. Technol., 33, 365-383.

McKellar, Q.A., 1997. Ecotoxicology and residues of anthelmintic compounds. Vet. Parasitol. 72, 413-435.

Mechineni, A., Kommuru, D.S., Gujja, S., Mosjidis, J.A., Miller, J.E., Burke, J.M., Ramsay, A., Mueller-Harvey, I., Kannan, G., Lee, J.H., Kouakou, B., Terrill, T.H., 2014. Effect of fall-grazed sericea lespedeza (Lespedeza cuneata) on gastrointestinal nematode infections of growing goats. Vet. Parasitol. 204, 221228.

Méndez-Ortiz, F.A., Sandoval-Castro, C.A., Ventura-Cordero, J., Sarmiento-Franco, L.A., Torres-Acosta, J.F.J., 2018. Condensed tannin intake and sheep performance: A meta-analysis on voluntary intake and live weight change. Anim. Feed Sci. Tech. 245, 67-76.

Moreno-Gonzalo, J., Ferre, I., Celaya, R., Frutos, P., Ferreira, L.M.M., Hervás, G., García, U., Ortega-Mora, L.M., Osoro, K., 2012. Potential use of heather to control gastrointestinal nematodes in goats. Small Ruminant Res. 103, 60-68.

Moreno-Gonzalo, J., Manolaraki, F., Frutos, P., Hervas, G., Celaya, R., Osoro, K., Ortega-Mora, L.M., Hoste, H., Ferre, I., 2013a. In vitro effect of heather 
(Ericaceae) extracts on different stages of Teladorsagia circumcincta and Haemonchus contortus. Vet. Parasitol. 197, 235-243.

734 Moreno-Gonzalo, J., Manolaraki, F., Frutos, P., Hervas, G., Celaya, R., Osoro, K., 735 Ortega-Mora, L.M., Hoste, H., Ferre, I., 2013b. In vitro effect of heather extracts 736 on Trichostrongylus colubriformis eggs, larvae and adults. Vet. Parasitol. 197, 586737594.

738 Moreno-Gonzalo, J., Osoro, K., Garcia, U., Frutos, P., Celaya, R., Ferreira, L.M.M., 739 Ortega-Mora, L.M., Ferre, I., 2014. Anthelmintic effect of heather in goats 740 experimentally infected with Trichostrongylus colubriformis. Parasitol. Res. 113, $741 \quad 693-699$.

742 Morgan, E. R., Aziz, N. A., Blanchard, A., Charlier, J., Charvet, C., Claerebout, E., 743 Geldhof, P., Greer, A. W., Hertzberg, H., Hodgkinson, J., Höglund, J., Hoste, H., 744 Kaplan, R. M., Martínez-Valladares, M., Mitchell, S., Ploeger, H. W., Rinaldi, L., 745 von Samson-Himmelstjerna, G., Sotiraki, S., Schnyder, M., Skuce, P., Bartley, D., 746 Kenyon, F., Thamsborg, S.M., Rose Vineer, H., de Waal, T. Williams, A.R., van 747 Wyk J.A., Vercruysse, J. 2019. 100 Questions in Livestock Helminthology $748 \quad$ Research. Trends Parasitol., 35(1), 52-71.

749 Mueller-Harvey, I., 2006. Unravelling the conundrum of tannins in animal nutrition $750 \quad$ and health. J. Sci. Food Agr. 86, 2010-2037.

751 Mueller-Harvey, I., Bee, G., Dohme-Meier, F., Hoste, H., Karonen, M., Kolliker, R., 752 Lüscher, A., Niderkorn, V., Pellikaan, W.F., Salminen, J.P., Skot, L., Smith, 753 L.M.J., Thamsborg, S.M., Totterdell, P., Wilkinson, I., Williams, A.R., Azuhnwi, 754 B.N., Baert, N., Grosse Brinkhaus A., Copani, G., Desrues, O., Drake, C., 755 Engstrom, M., Fryganas, C., Girard, M., Huyen, N.T., Kempf, K., Malisch, C., 756 Mora-Ortiz, M., Quijada, J., Ramsay, A., Ropiak, H.M., Waghorn, G.C., 2019. 
Benefits of condensed tannins in forage legumes fed to ruminants: importance of structure, concentration and diet composition. Crop Sci. 59, 861-885.

759 Mupeyo, B., Barry, T.N., Pomroy, W.E., Ramírez-Restrepo, C. A., López-Villalobos, 760 N., Pernthaner, A., 2011. Effects of feeding willow (Salix spp.) upon death of 761 established parasites and parasite fecundity. Anim. Feed Sci. Tech. 164(1-2), 8-20.

762 Niezen, J.H., Waghorn, T.S., Charleston, W.A.G., Waghorn, G.C., 1995. Growth and 763 gastrointestinal nematode parasitism in lambs grazing either lucerne (Medicago 764 sativa) or sulla (Hedysarum coronarium) which contains condensed tannins. J. $765 \quad$ Agric. Sci 125, 281-289.

766 Niezen, J.H., Charleston, W.A.G., Robertson, H.A., Shelton, D., Waghorn, G.C., 767 Green, R., 2002. The effect of feeding sulla (Hedysarum coronarium) or lucerne 768 (Medicago sativa) on lamb parasite burdens and development of immunity to 769 gastrointestinal nematodes. Vet. Parasitol. 105, 229-245.

770 Novobilsky, A., Stringano, E., Hayot Carbonero, C., Smith, L.M.J., Enemark, H.L., 771 Mueller-Harvey, I., Thamsborg, S.M., 2013. In vitro effects of extracts and 772 purified tannins of sainfoin (Onobrychis viciifolia) against two cattle nematodes. $773 \quad$ Vet. Parasitol. 196, 532-537.

774 NRC (National Research Council) 2007 Nutrient Requirements of Small Ruminants: 775 Sheep, Goats, Cervids, and New World Camelids. Washington: The National 776 Academies Press.

777 Paolini, V., De La Farge, F., Prevot, F., Dorchies, P., Hoste, H., 2005. Effects of the 778 repeated distribution of sainfoin hay on the resistance and the resilience of goats 779 naturally infected with gastrointestinal nematodes. Vet. Parasitol. 127, 277-283.

780 Papachristou, T.G., Dziba, L.E., Provenza, F.D., 2005. Foraging ecology of goats and 781 sheep on wooded rangelands. Small Ruminant Res. 59, 141-156. 
Perry, B.D., Randolph, T.F., 1999. Improving the assessment of the economic impact of parasitic diseases and of their control in production animals. Vet. Parasitol. 84, 145-168.

Priolo, A., Lanza, M., Biondi, L., Pappalardo, P, Young, O.A., 1998. Effect of partially replacing dietary barley with $20 \%$ carob pulp on post- weaning growth, and carcass and meat characteristics of Comisana lambs. Meat Sci. 50, 355-363.

Priolo, A., Waghorn, G.C., Lanza, M., Biondi, L., Pennisi P., 2000. Polyethylene glycol as a means to reducing the impact of condensed tannins in carob pulp: effect on lamb growth and meat quality. J. Anim. Sci., 78, 810-816.

Priolo, A., Lanza, M., Bella, M., Pennisi, P., Fasone, V., Biondi, L., 2002. Reducing the impact of condensed tannins in a diet based on carob pulp using two levels of polyethylene glycol: lamb growth, digestion and meat quality Anim. Res., 51305 313.

Quijada, J., 2015. Relation structure/activité de tanins bioactifs contre les nématodes gastrointestinaux (Haemonchus contortus) parasites des petits ruminants. Doctorat de l'Université de Toulouse 235pp.

Quijada, J., Drake, C., Gaudin, E., El-Korso, R., Hoste, H., Mueller-Harvey, I., 2018. Condensed tannin changes along the digestive tract in lambs fed with sainfoin pellets or hazelnut skins. J. Agric. Food Chem. 66, 2136-2142.

Ropiak, H.M., Ramsay, A., Mueller-Harvey, I., 2016. Condensed tannins in extracts from European medicinal plants and herbal products. J. Pharmaceut. Biomed. 121, $225-231$.

Ríos-de Alvarez, L., Greer, A.W., Jackson, F., Athanasiadou, S., Kyriazakis, I., Huntley, J.F., 2008. The effect of dietary sainfoin (Onobrychis viciifolia) on local 

1117-1124.

808

809

Roepstorff, A., Nansen, P., 1998. Epidemiology Diagnosis and Control of helminth parasites of swine. FAO Animal Health Manual Rome, 51-56pp.

Saratsis, A., Voutzourakis, N., Theodosiou, T., Stefanakis, A., Sotiraki, S., 2016. The effect of sainfoin (Onobrychis viciifolia) and carob pods (Ceratonia siliqua) feeding regimes on the control of lamb coccidiosis Parasitol. Res. 115, 2233-2242. doi:10.1007/s00436-016-4966-9

Shaik, S.A., Terrill, T.H., Miller, J.E., Kouakou, B., Kannan, G., Kallu, R.K., Mosjidis, J.A., 2004. Effects of feeding sericea lespedeza hay to goats infected with Haemonchus contortus. S. Afr. J. Anim. Sci. 34, 248-250.

Shaik, S.A., Terrill, T.H., Miller, J.E., Kouakou, B., Kannan, G., Kaplan, R.M., Burke, J.M., Mosjidis, J.A., 2006. Sericea lespedeza hay as a natural deworming agent against gastrointestinal nematode infection in goats. Vet. Parasitol. 139, 150157.

Silanikove, N., Gilboa, N., Nir, I., Perevolotsky, A., Nitsan, Z., 1996. Effect of a daily supplementation of polyethylene glycol on intake and digestion of tannincontaining leaves (Quercus calliprinos, Pistacia lentiscus and Ceratonia siliqua) by goats. J. Agric. Food Chem. 44, 199-205.

Silanikove, N., Landau, S., Or, D., Kababya, D., Bruckental, I., Nitsan, Z., 2006. Analytical approach and effects of condensed tannins in carob pods (Ceratonia siliqua) on feed intake, digestive and metabolic responses of kids. Livest. Sci. 99, 29-38.

Silva Soares, S.C., de Lima, G.C., Laurentiz, A.C., Féboli, A., dos Anjos, L.A., de Paula Carlis, M.S., da Silva Filardi, R., da Silva de Laurentiza, R., 2018. In vitro 
anthelmintic activity of grape pomace extract against gastrointestinal nematodes of naturally infected sheep. Int. J. Vet. Sci. Med. 6, 243-247.

833 Stear, M.J., Doliglska, M., Donskow-Schmelter, K., 2007. Alternatives to 834 anthelmintics for the control of nematodes in livestock. Parasitology 134, 139-151. doi:10.1017/S0031182006001557

836 Terrill, T.H., Miller, J.E., Burke, J.M., Mosjidis, J.A., Kaplan, R.M., 2012.

837 Experiences with integrated concepts for the control of Haemonchus contortus in 838 sheep and goats in the United States. Vet. Parasitol. 186, 28-37.

839 Theodoridou, K., Aufrère, J., Andueza, D., Le Morvan, A., Picard, F., Pourrat, J., 840 Baumont, R., 2012. Effects of condensed tannins in wrapped silage bales of sainfoin 841 (Onobrychis viciifolia) on in vivo and in situ digestion in sheep. Animal 6, 245-253.

842 Torres-Acosta, J.F.J., Mendoza-de-Gives, P., Aguilar-Caballero, A.J., Cueíllar-Ordaz, 843 J.A., 2012. Anthelmintic resistance in sheep farms: update of the situation in the 844 American continent. Vet. Parasitol. 189, 89-96.

845 Waghorn, G., 2008. Beneficial and detrimental effects of dietary condensed tannins 846 for sustainable sheep and goat production-Progress and challenges. Anim. Feed $847 \quad$ Sci. Tech. $147,116-139$.

848 Waller, P.J., 2006. Sustainable nematode parasite control strategies for ruminant 849 livestock by grazing management and biological control. Anim. Feed Sci. Tech. $850 \quad 126,277-289$.

851 Williams, A.R., Fryganas, C., Ramsay, A., Mueller-Harvey, I., Thamsborg, S.M., 852 2014. Direct anthelmintic effects of condensed tannins from diverse plant sources 853 against Ascaris suum. PLoS ONE, 9(5), e97053. 854 doi:10.1371/journal.pone.0097053 
Table 1: Experimental design $(\mathrm{CaBP}=\mathrm{Carob} ; \mathrm{CaBP}+\mathrm{PEG}=\mathrm{Carob}+\mathrm{PEG} ; \mathrm{C}=\mathrm{Control} ; \mathrm{C}+\mathrm{PEG}=\mathrm{Control}+\mathrm{PEG} ; \mathrm{CaBP}+\mathrm{S}=\mathrm{Carob}+\mathrm{Sainfoin}$; $\mathrm{S}=$ Sainfoin)

\begin{tabular}{|c|c|c|c|c|c|c|c|}
\hline Trial & Groups & $\begin{array}{l}\text { Lambs/ } \\
\text { group }\end{array}$ & $\begin{array}{l}\text { Mean BW } \\
\text { at start } \\
\pm \text { s.d. }(\mathrm{kg})\end{array}$ & $\begin{array}{l}\text { Day } \\
\text { feeding } \\
\text { started }\end{array}$ & $\begin{array}{l}\text { Infection } \\
\text { Day }\end{array}$ & $\begin{array}{l}\text { Inoculation } \\
\text { dose (L3) }\end{array}$ & $\begin{array}{l}\text { Day } \\
\text { trial } \\
\text { ended }\end{array}$ \\
\hline \multirow{5}{*}{1} & CaBP $0 \%$ & \multirow{5}{*}{7} & $25.8 \pm 1.1$ & \multirow{5}{*}{-14} & \multirow{5}{*}{0} & $12000 \mathrm{H}$ & \multirow{5}{*}{49} \\
\hline & CaBP $3 \%$ & & $26.2 \pm 3.7$ & & & contortus & \\
\hline & CaBP $6 \%$ & & $25.2 \pm 2.6$ & & & $\&$ & \\
\hline & СaBP $9 \%$ & & $27.1 \pm 3.5$ & & & \multirow{2}{*}{$\begin{array}{l}12,000 \mathrm{~T} . \\
\text { colubriformis }\end{array}$} & \\
\hline & CaBP $12 \%$ & & $26.4 \pm 2.8$ & & & & \\
\hline \multirow{4}{*}{2} & $\mathrm{C}$ & \multirow{4}{*}{6} & $26.4 \pm 2.7$ & \multirow{4}{*}{21} & \multirow{4}{*}{0} & 8,000 L3 H. & \multirow{4}{*}{37} \\
\hline & $\mathrm{C}+\mathrm{PEG}$ & & $26.5 \pm 2.6$ & & & contortus & \\
\hline & & & $26.3 \pm 2.4$ & & & $\&$ & \\
\hline & $\mathrm{CaBP}+\mathrm{PEG}$ & & $27.0 \pm 1.7$ & & & $\begin{array}{l}16,000 \mathrm{~L} 3 \mathrm{~T} \text {. } \\
\text { colubriformis }\end{array}$ & \\
\hline \multirow{4}{*}{3} & $\mathrm{C}$ & \multirow{4}{*}{6} & $27.0 \pm 3.1$ & \multirow{4}{*}{-14} & \multirow{4}{*}{0} & 12,000 L3 $H$. & \multirow{4}{*}{37} \\
\hline & $\mathrm{CaBP}(12 \%)$ & & $27.1 \pm 2.5$ & & & contortus & \\
\hline & $\mathrm{CaBP}+\mathrm{S}$ & & $27.1 \pm 2.9$ & & & $\&$ & \\
\hline & S & & $26.8 \pm 3.2$ & & & $\begin{array}{l}\text { 12,000 L3 T. } \\
\text { colubriformis }\end{array}$ & \\
\hline
\end{tabular}


Table 2. Condensed tannin concentrations (expressed as g CT/100 g DW) measured either with the acetone-HCl-butanol or the thiolysis assays as well as tannin compositions in the two different feeds [abbreviations: \% refers to molar percentages of galloylation, prodelphinidins (PD), procyanidins (PC), cis- or trans- flavan-3-ol subunits; mean degree of polymerisation (mDP)].

ND: non detected

\begin{tabular}{|c|c|c|c|c|c|c|}
\hline & $\%$ galloylation & $\mathbf{P D} / \mathrm{PC}$ & $\begin{array}{l}\text { Tannins (acetone- } \\
\text { HCl/butanol) }\end{array}$ & $\begin{array}{l}\text { Tannins } \\
\text { (thiolysis) }\end{array}$ & $\mathbf{m D P}$ & cis/trans-flavan-3-ols \\
\hline Carob meal & $41.1( \pm 0.6)$ & $96.7 / 3.3( \pm 0.1)$ & $5.84( \pm 0.2)$ & $7.20( \pm 0.0)$ & $31.2( \pm 0.1)$ & $45.9 / 54.1( \pm 0.0)$ \\
\hline Sainfoin pellets ${ }^{\mathrm{a}}$ & ND & $74.8 / 25.2( \pm 0.5)$ & $6.50( \pm 0.3)$ & $1.70( \pm 0.1)$ & $11.5( \pm 0.3)$ & $85.3 / 14.7( \pm 0.1)$ \\
\hline
\end{tabular}

${ }^{\mathrm{a}}$ The same sainfoin pellets were used in another study (Quijada et al., 2018) and the data are reported here for comparison purposes. 
Table 3.

Trial 1: Effect of diet regimes containing different concentration of Carob (CaBP) on adult worms recovered at necropsy in the different experimental lamb groups. Adult worm counts (AWC) shown as arithmetic mean of adult worms (and SD in brackets) per group fed different amount of Carob pod meal $(\mathrm{CaBP}=\mathrm{Carob})$.

\begin{tabular}{|c|c|c|c|c|c|c|}
\hline \multirow{2}{*}{$\begin{array}{l}\text { Treatment } \\
\text { Group }\end{array}$} & \multicolumn{3}{|c|}{ H. contortus } & \multicolumn{3}{|c|}{ T. colubriformis } \\
\hline & Female & Male & Total & Female & Male & Total \\
\hline 0\% СaBP & $\begin{array}{c}2,777 \\
( \pm 1,579)\end{array}$ & $\begin{array}{c}2,331 \\
( \pm 1,382)\end{array}$ & $\begin{array}{c}5,109 \\
( \pm 2,802)\end{array}$ & $\begin{array}{c}2,063 \\
( \pm 534)\end{array}$ & $\begin{array}{c}1,097 \\
( \pm 471)\end{array}$ & $\begin{array}{c}3,160 \\
( \pm 944)\end{array}$ \\
\hline $3 \%$ CaBP & $\begin{array}{c}2,789 \\
( \pm 1,606)\end{array}$ & $\begin{array}{c}2,006 \\
( \pm 1,117)\end{array}$ & $\begin{array}{c}4,794 \\
( \pm 2,709)\end{array}$ & $\begin{array}{c}2,493 \\
( \pm 986)\end{array}$ & $\begin{array}{c}1,163 \\
( \pm 568)\end{array}$ & $\begin{array}{c}3,656 \\
( \pm 1,461)\end{array}$ \\
\hline 6\% СаBP & $\begin{array}{c}3,584 \\
( \pm 1,570)\end{array}$ & $\begin{array}{c}2,570 \\
( \pm 1,178)\end{array}$ & $\begin{array}{c}6,154 \\
( \pm 2,595)\end{array}$ & $\begin{array}{c}2,514 \\
( \pm 497)\end{array}$ & $\begin{array}{c}903 \\
( \pm 676)\end{array}$ & $\begin{array}{c}3,417 \\
( \pm 1,073)\end{array}$ \\
\hline $12 \% \mathrm{CaBP}$ & $\begin{array}{c}2,160 \\
( \pm 1,362)\end{array}$ & $\begin{array}{c}2,039 \\
( \pm 1,212)\end{array}$ & $\begin{array}{c}4,199 \\
( \pm 2,422)\end{array}$ & $\begin{array}{c}1,550 \\
( \pm 801)\end{array}$ & $\begin{array}{c}944 \\
( \pm 630)\end{array}$ & $\begin{array}{c}2,494 \\
( \pm 1,416)\end{array}$ \\
\hline
\end{tabular}


Table 4.

Trial 2: Effect of PEG intake on adult worms recovered at necropsy in the different groups of lambs fed with carob rich diet (Groups: $\mathrm{CaBP}(\mathrm{Carob})$ and $\mathrm{CaBP}+\mathrm{PEG}$ (Carob+PEG)) or not (Groups: C (Control), C+PEG (Control+PEG)). Adult worm counts (AWC) shown as arithmetic mean of adult worms (female, male, total) (and SD in brackets) per group.

\begin{tabular}{|c|c|c|c|c|c|c|}
\hline \multirow{2}{*}{$\begin{array}{l}\text { Treatment } \\
\text { Group }\end{array}$} & \multicolumn{3}{|c|}{ H. contortus } & \multicolumn{3}{|c|}{ T. colubriformis } \\
\hline & Female & Male & Total & Female & Male & Total \\
\hline $\mathbf{C}$ & $\begin{array}{c}897 \\
( \pm 736)\end{array}$ & $\begin{array}{c}584 \\
( \pm 461)\end{array}$ & $\begin{array}{c}1,480^{\mathbf{a}} \\
( \pm 1,194)\end{array}$ & $\begin{array}{c}5,783 \\
( \pm 2,104)\end{array}$ & $\begin{array}{c}4,382 \\
( \pm 1,529)\end{array}$ & $\begin{array}{c}10,166 \\
( \pm 3,599)\end{array}$ \\
\hline C+PEG & $\begin{array}{c}1,002 \\
( \pm 323)\end{array}$ & $\begin{array}{c}710 \\
( \pm 279)\end{array}$ & $\begin{array}{l}1,712^{a} \\
( \pm 593)\end{array}$ & $\begin{array}{c}6,028 \\
( \pm 2,740)\end{array}$ & $\begin{array}{c}4,713 \\
( \pm 2,067)\end{array}$ & $\begin{array}{c}10,742 \\
( \pm 4,776)\end{array}$ \\
\hline CaBP & $\begin{array}{c}288 \\
( \pm 220)\end{array}$ & $\begin{array}{c}243 \\
( \pm 199)\end{array}$ & $\begin{array}{c}532^{b} \\
( \pm 399)\end{array}$ & $\begin{array}{c}5,397 \\
( \pm 2,280)\end{array}$ & $\begin{array}{c}4,882 \\
( \pm 2,171)\end{array}$ & $\begin{array}{c}10,279 \\
( \pm 4,439)\end{array}$ \\
\hline CaBP+PEG & $\begin{array}{c}701 \\
( \pm 250)\end{array}$ & $\begin{array}{c}617 \\
( \pm 178)\end{array}$ & $\begin{array}{l}1,318^{a} \\
( \pm 424)\end{array}$ & $\begin{array}{c}5,751 \\
( \pm 2,387)\end{array}$ & $\begin{array}{c}5,303 \\
( \pm 1,743)\end{array}$ & $\begin{array}{c}11,054 \\
( \pm 4,091)\end{array}$ \\
\hline
\end{tabular}


Table 5.

Trial 3: Effect of diet regimes containing different condensed tannin diets on adult worms recovered at necropsy in the different experimental lamb groups $\mathrm{C}$ (Control), CaBP (Carob), S (Sainfoin pellets), CaBP+S (Carob+Sainfoin pellets). Adult worm counts (AWC) shown as arithmetic mean of adult worms (female, male, total) (and SD in brackets) per group.

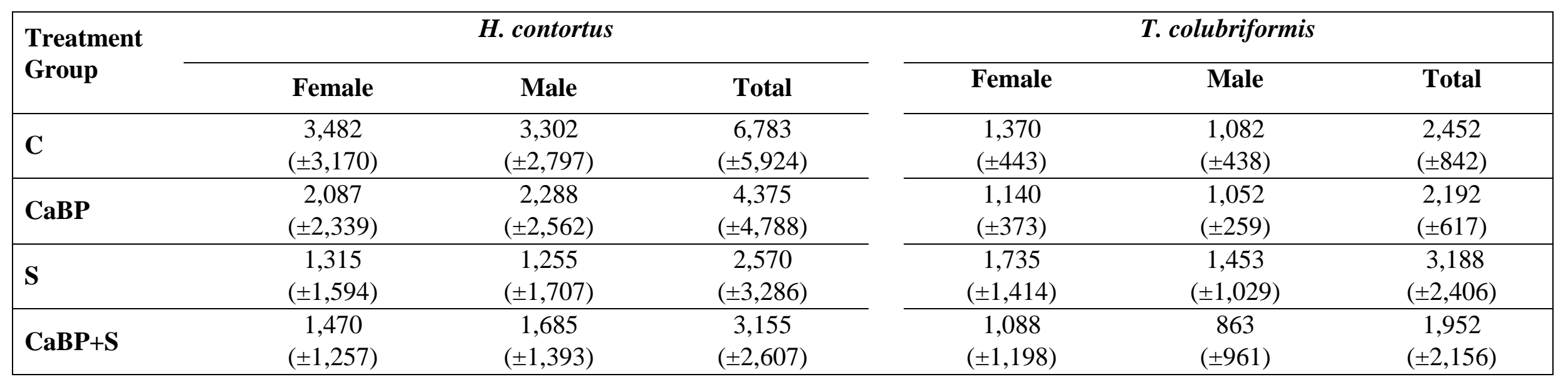


Figure 1. Trial 1: Effect of diet regimes containing different amounts of Carob pod meal (CaBP) on A) faecal egg counts (FEC) on Day 0 to 49 ) (SD in table below) and B) box-plots for female worm fecundity (95\% confidence interval) in the different experimental lambs for Haemonchus contortus and Trichostrongylus colubriformis.

A.

\section{FEC}

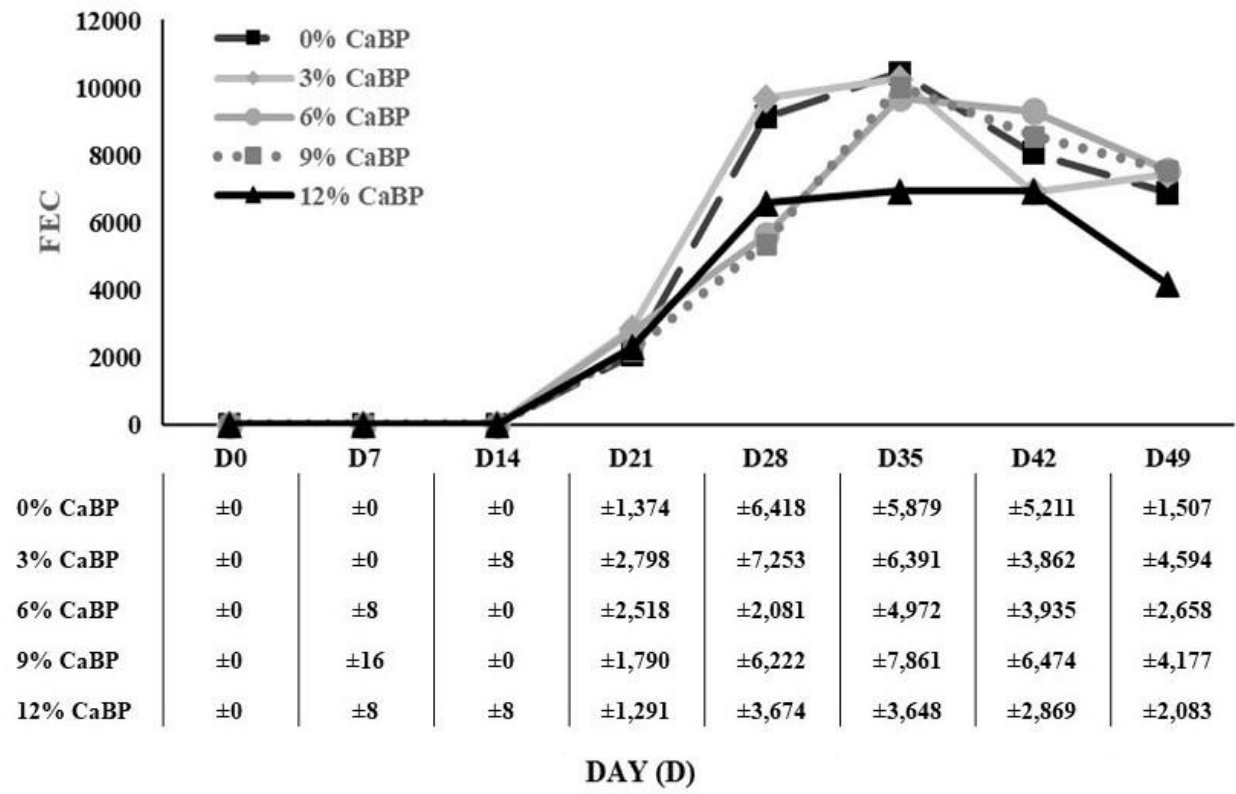

B.

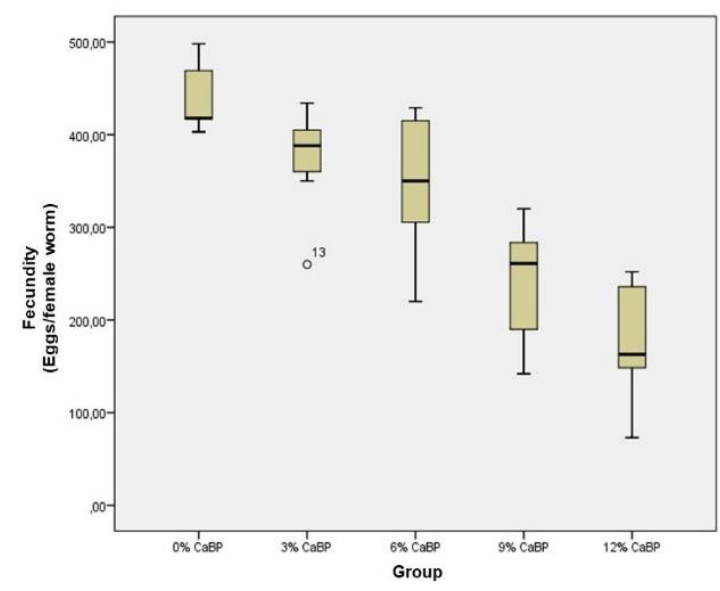

i. H. contortus

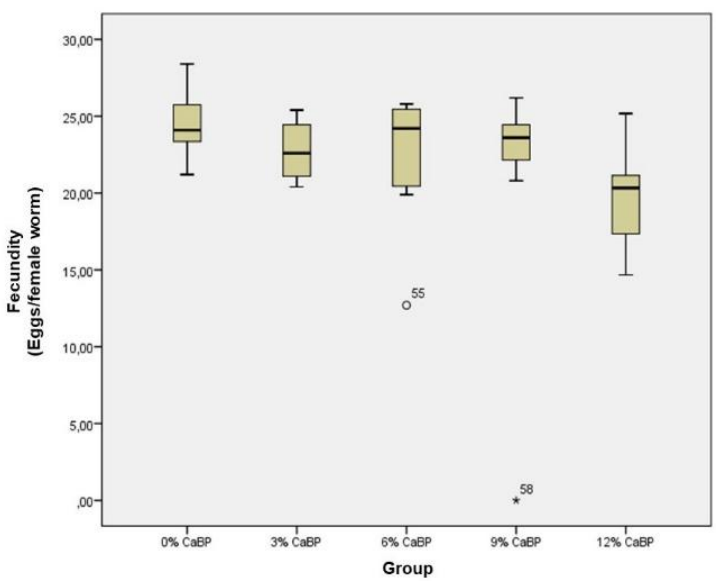

ii. T. colubriformis 
Figure 2. Trial 2: Effect of PEG intake on A) faecal egg counts (FEC) on Day 21 to 37 (SD in table below) and B) box-plots for female worm fecundity (95\% confidence interval) for Haemonchus contortus and Trichostrongylus colubriformis in the different experimental lambs fed with carob pods meal at $12 \%(\mathrm{CaBP}$ and $\mathrm{CaBP}+\mathrm{PEG})$ or served as Controls $(\mathrm{C}$ and $\mathrm{C}+\mathrm{PEG})$.

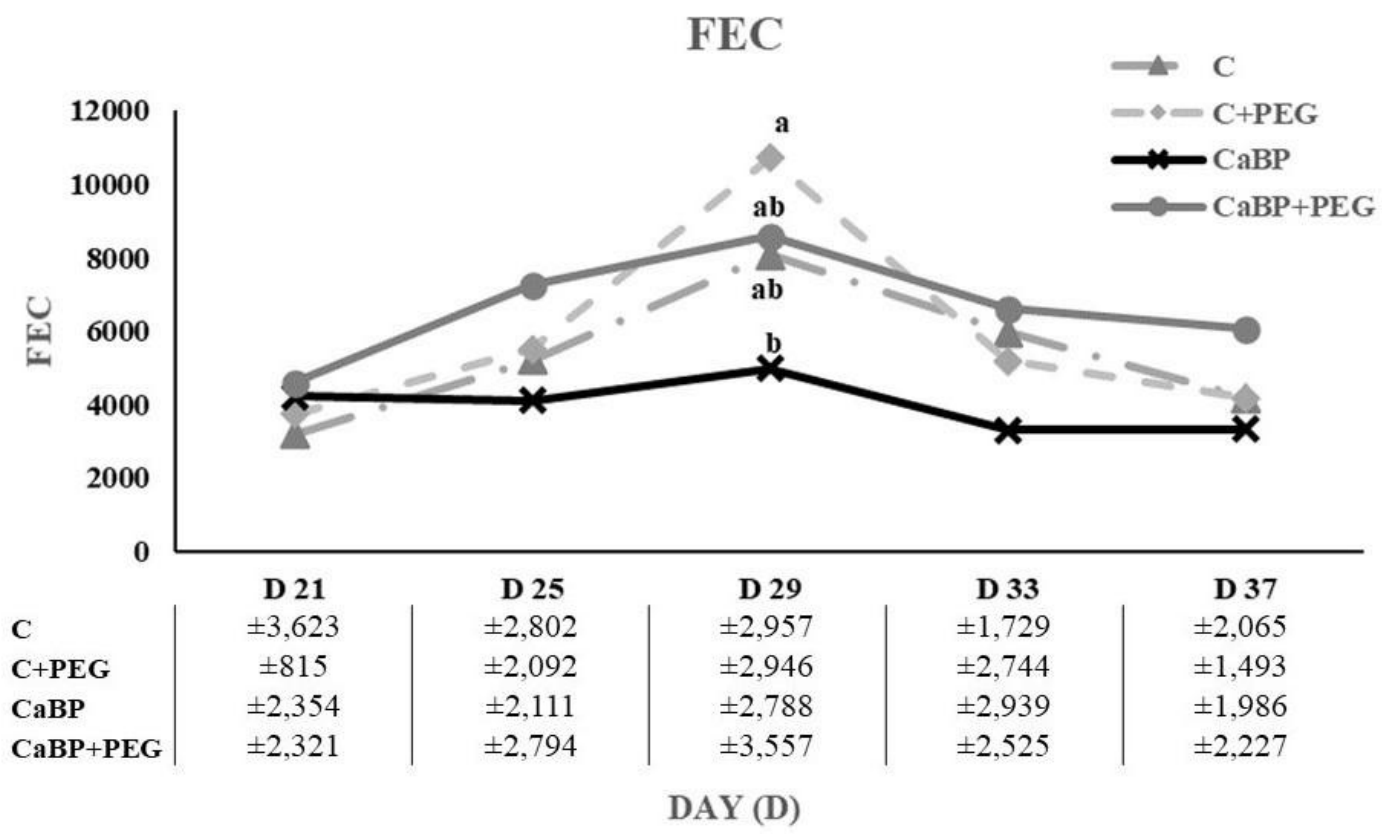

B.

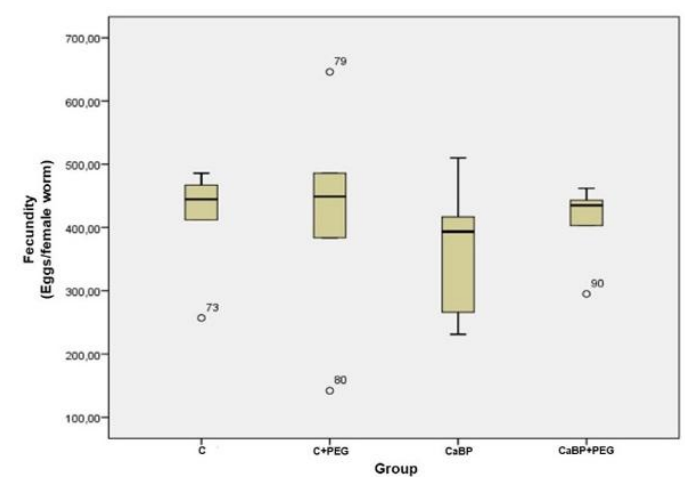

i. H. contortus

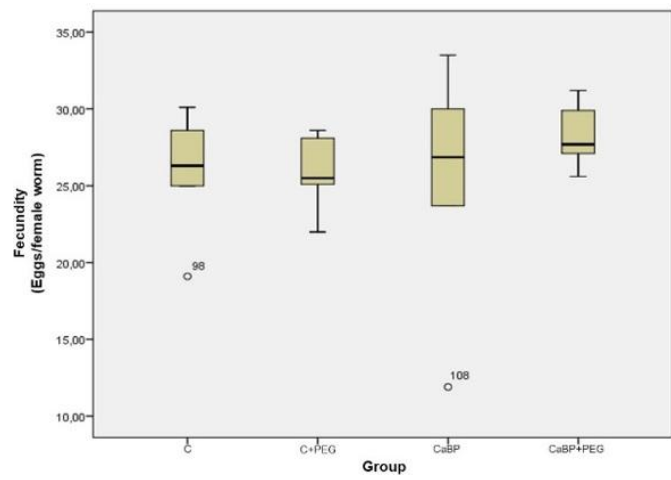

ii. T. colubriformis 
Figure 3. Trial 3: Effect of diet regimes containing different condensed tannin diets on A) faecal egg counts (FEC) on Day 7 to 37 (SD in table below) and B) box-plots for female worm fecundity (95\% confidence interval), in the different experimental lambs groups $\mathrm{C}$ (Control), $\mathrm{CaBP}$ (Carob), $\mathrm{S}$ (Sainfoin pellets), $\mathrm{CaBP}+\mathrm{S}$ (Carob+Sainfoin pellets) for Haemonchus contortus and Trichostrongylus colubriformis.

A.

\section{FEC}

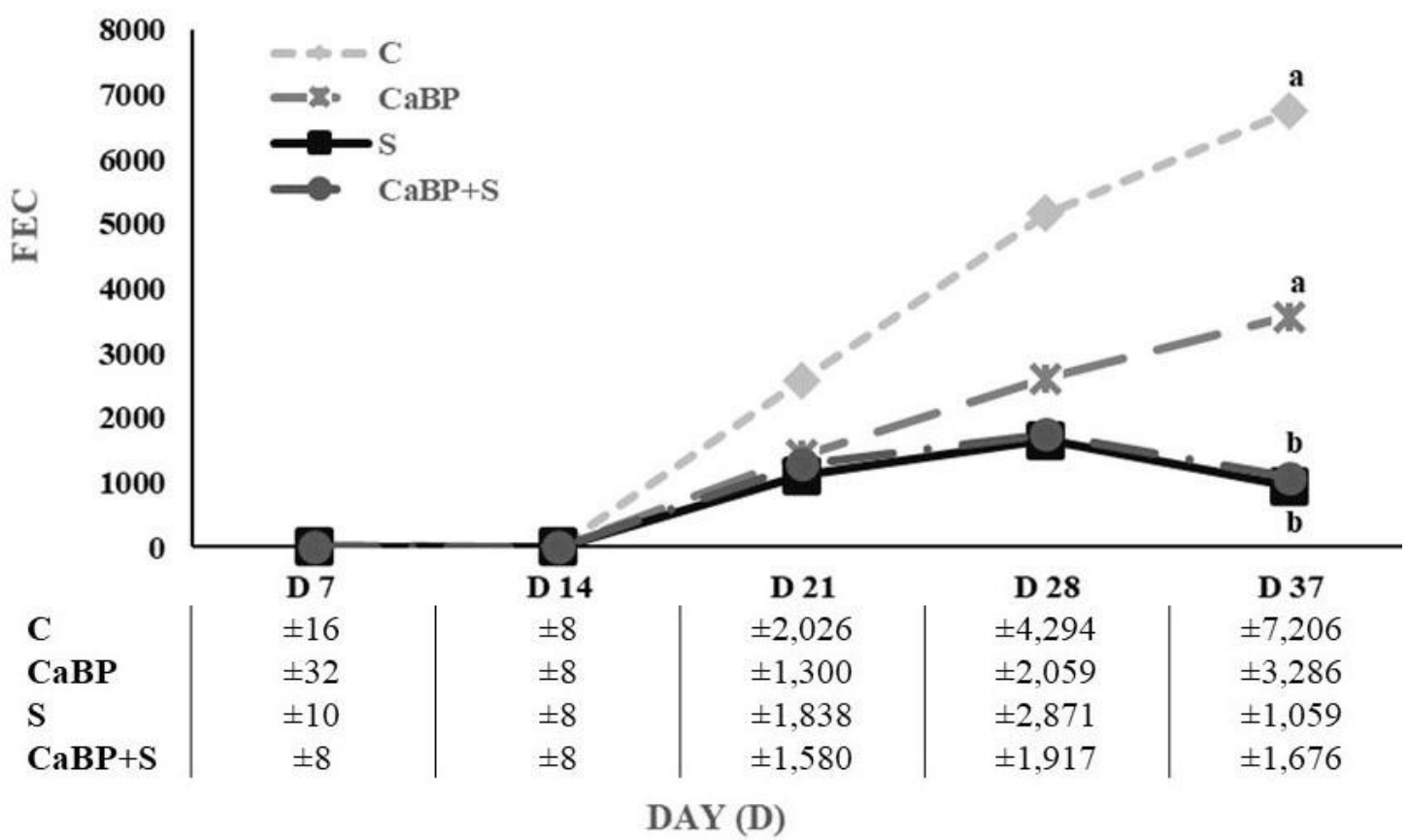

B.

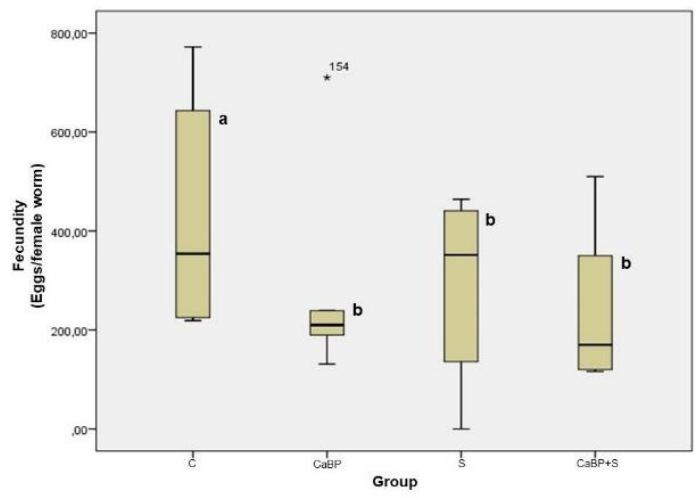

i. H. contortus

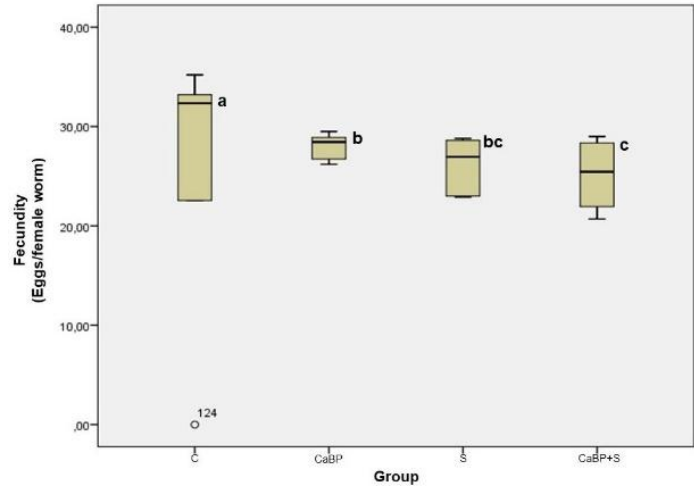

ii. T. colubriformis 

Files to appear as online only publications
Click here to download Files to appear as o

Click here to download Files to appear as online only publications: diet_supplementary.docx

Click here to download Files to appear as online only publications: diet supplementary.docx

(1)

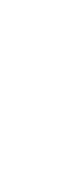

$\sqrt{3}$

(1)

(1)

$\sqrt{2}$

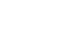

.

.

.

.

.

.

.

.

.

.

.

.

.

.

.

.

.

.

.

.

.

.

.

.

.

.

.

.

.

.

.

.

.

. 


\section{${ }^{*}$ Conflict of Interest}

\section{Declaration of interests}

$\bigotimes$ The authors declare that they have no known competing financial interests or personal relationships that could have appeared to influence the work reported in this paper.

$\square$ The authors declare the following financial interests/personal relationships which may be considered as potential competing interests:

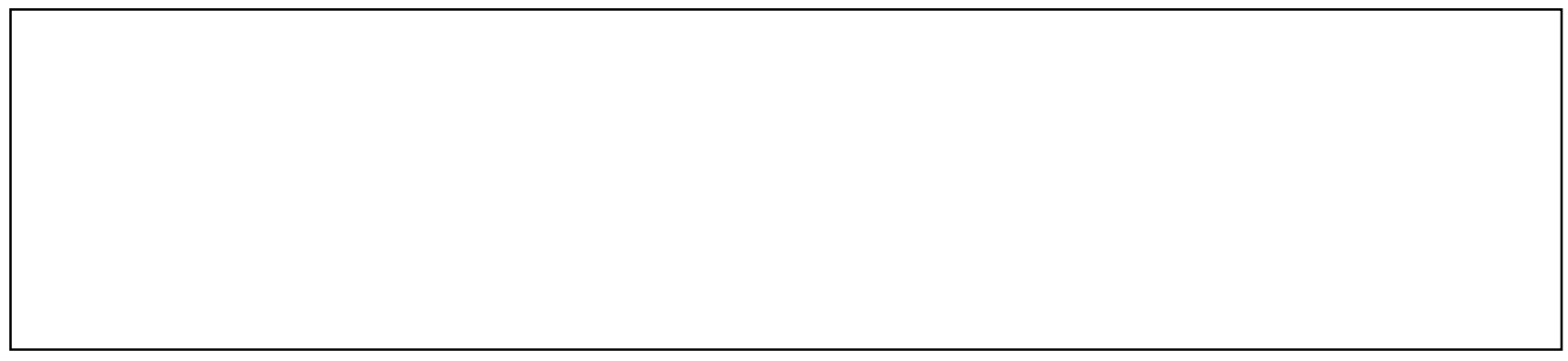




\section{Author Contribution Statement}

SARATSI K was a PhD student and the paper is part of her PhD Thesis, SOTIRAKI S, HADJIGEORGIOU I, and HOSTE $\mathbf{H}$ were the Supervisors of her Thesis including the current work. VOUTZOURAKIS $\mathbf{N}$ and STEFANAKIS $\mathbf{A}$ are specialist in animal nutrition and supporting the preparation of ration and acquiring the samples, data interpretation and writing the paper. TZANIDAKIS $\mathbf{N}$, is a veterinarian supporting with laboratory techniques, THAMSBORG SM, is a senior scientists coordinator of CARES project who supervised the trials and supported data analyses, interpretation and writing the paper and MUELLERHARVEY $\mathbf{I}$ is a senior researcher expert in tannin analyses who supported in chemical analysis of the feeds and data interpretation and writing the paper.

According to CRediT:

SARATSI K: Conceptualization, Visualization, Investigation, Resources, Formal Analyses, Writing- Original draft preparation, Reviewing and Editing, SOTIRAKI S, HADJIGEORGIOU I, HOSTE $\mathbf{H}$ and THAMSBORG SM: Conceptualization, Supervision, Writing, Reviewing and Editing. VOUTZOURAKIS N, TZANIDAKIS $\mathbf{N}$ and STEFANAKIS A Investigation, Resources, Reviewing and Editing, MUELLER-HARVEY I: Methodology, Investigation, Reviewing and Editing 